\title{
Evolución estratigráfica de la cuenca Los Barriles, Baja California Sur, México
}

\author{
Tobias Schwennicke*, Diana María Santisteban-Mendívil, José Antonio Pérez-Venzor, \\ Mara Yadira Cortés-Martínez y Elvia Plata-Hernández
}

Departamento Académico de Ciencias de la Tierra, Universidad Autónoma de Baja California Sur, Apartado Postal 19-B, 23080 La Paz, Baja California Sur, México.

*tobias@uabcs.mx

\section{RESUMEN}

La cuenca Los Barriles, al norte de la cuenca San José del Cabo, forma parte de la Provincia Extensional del Golfo. Es un medio graben, limitado en su lado oeste por el sistema de fallas Los Barriles. Nuestra investigación confirma que éste no es parte de la falla San José del Cabo, sino una estructura independiente. El relleno sedimentario se constituye de tres secuencias estratigráficas: SE 1, SE 2 y SE 3. La SE 1 está conformada por las formaciones Los Barriles y Trinidad. La Formación Los Barriles se compone de conglomerado y arenisca formados en abanicos aluviales y está en contacto con el basamento plutónico y metamórfico cretácico en el oeste, mediante la falla Los Barriles, y en el este a través de una discordancia. La Formación Trinidad está constituida por lodolita y arenisca de origen marino. Ambas formaciones se interdigitan e integran abanicos deltaicos sin capas frontales de crecimiento progresivo, sugiriendo una rápida subsidencia del bloque de techo a lo largo de la falla marginal. Nanofósiles calcáreos en la SE 1 indican una edad en la nanozona NN11 (Tortoniano tardío - Messiniano), señalando que la subsidencia de la cuenca inició en el Mioceno tardío, antes de la activación de la falla San José del Cabo en el Plioceno. La Formación Refugio (SE 2), compuesta por arenisca y conglomerado fosilífero de origen marino somero, cubre discordantemente a la Formación Trinidad y se interdigita lateralmente con la parte superior de la Formación Los Barriles, conformando un abanico deltaico de aguas someras, probablemente de edad pliocénica. La Formación El Chorro del Pleistoceno sobreyace discordantemente todas las unidades anteriores y cubre localmente al sistema de fallas Los Barriles. Está compuesta por arenisca y conglomerado depositados en abanicos aluviales y se interdigita hacia la línea de costa actual con conglomerado y arenisca fosilíferos marinos formados durante el último período interglacial; ambos constituyen la SE 3.

Palabras claves: Provincia Extensional del Golfo; cuenca Los Barriles; cuenca San José del Cabo; abanicos deltaicos; México.

\section{ABSTRACT}

The Los Barriles basin, located north of the San José del Cabo basin, is part of the Gulf Extensional Province. It is a half graben bounded by the Los Barriles fault system on its western side. Our study confirms that this system is not part of the San José del Cabo fault but an independent structure. The basin fill includes three stratigraphic sequences: SE 1,
SE 2, and SE 3. Los Barriles and Trinidad Formations constitute SE 1. The Los Barriles Formation is in contact with the marginal fault and on the eastern margin it rests unconformably upon the plutonic and metamorphic basement. The unit is composed of conglomerate and sandstone formed in alluvial fans. The marine Trinidad Formation is composed of sandstone and mudstone. Both formations interfinger and constitute fan deltas without foresets, suggesting rapid subsidence along the Los Barriles fault. Calcareous nannofossils in SE 1 point toward an age in the nannofossil zone NN11 (Late Tortonian-Messinian). Thus, faulting and subsidence occurred since the late Miocene, indicating that the Los Barriles fault system is older than the San José del Cabo fault, which had been activated during the Pliocene. The Refugio Formation (SE 2) rests unconformably on the Trinidad Formation; it consists of fossiliferous sandstone and conglomerate originated in a shallow marine coastal setting. Laterally, it interfingers with younger portions of the Los Barriles Formation, forming a fan delta setting of probable Pliocene age. The El Chorro Formation unconformably covers all older units and, locally, even Los Barriles fault system. It comprises sandstone and conglomerate formed in an alluvial fan depositional environment. These deposits interfinger towards the present coastline with fossiliferous sandstone and conglomerate formed during the last interglacial period, representing SE 3.

Key words: Gulf Extensional Province; Los Barriles basin; San José del Cabo basin; fan deltas; Mexico.

\section{INTRODUCCIÓN}

En el borde oriental de la península de Baja California existe una serie de cuencas sedimentarias formadas a partir del Mioceno tardío durante la apertura del golfo de California. Una de éstas es la cuenca San José del Cabo (Figura 1), ubicada en el extremo sur de la misma península; es un medio graben limitado en su margen occidental por la falla del mismo nombre (Martínez-Gutiérrez y Sethi, 1997). El área al noroeste de Los Barriles (Figura 1), igualmente, es un medio graben aunque de menor dimensión que la cuenca San José del Cabo. Está limitada en el oeste por una falla maestra, la cual ha sido considerada parte de la falla San José del Cabo (Bravo-Pérez, 2002) o interpretada como una estructura independiente (Geoffroy y Pronost, 2010; Bot et al., 2016). El presente estudio confirma que este sistema de fallas marginales es independiente de la falla San José del Cabo, lo que concuerda con la interpretación de Bot et al. (2016). Geoffroy y Pronost (2010) y Bot et al. (2016) llamaron a esta cuenca Los Barriles. Además, reconocieron 


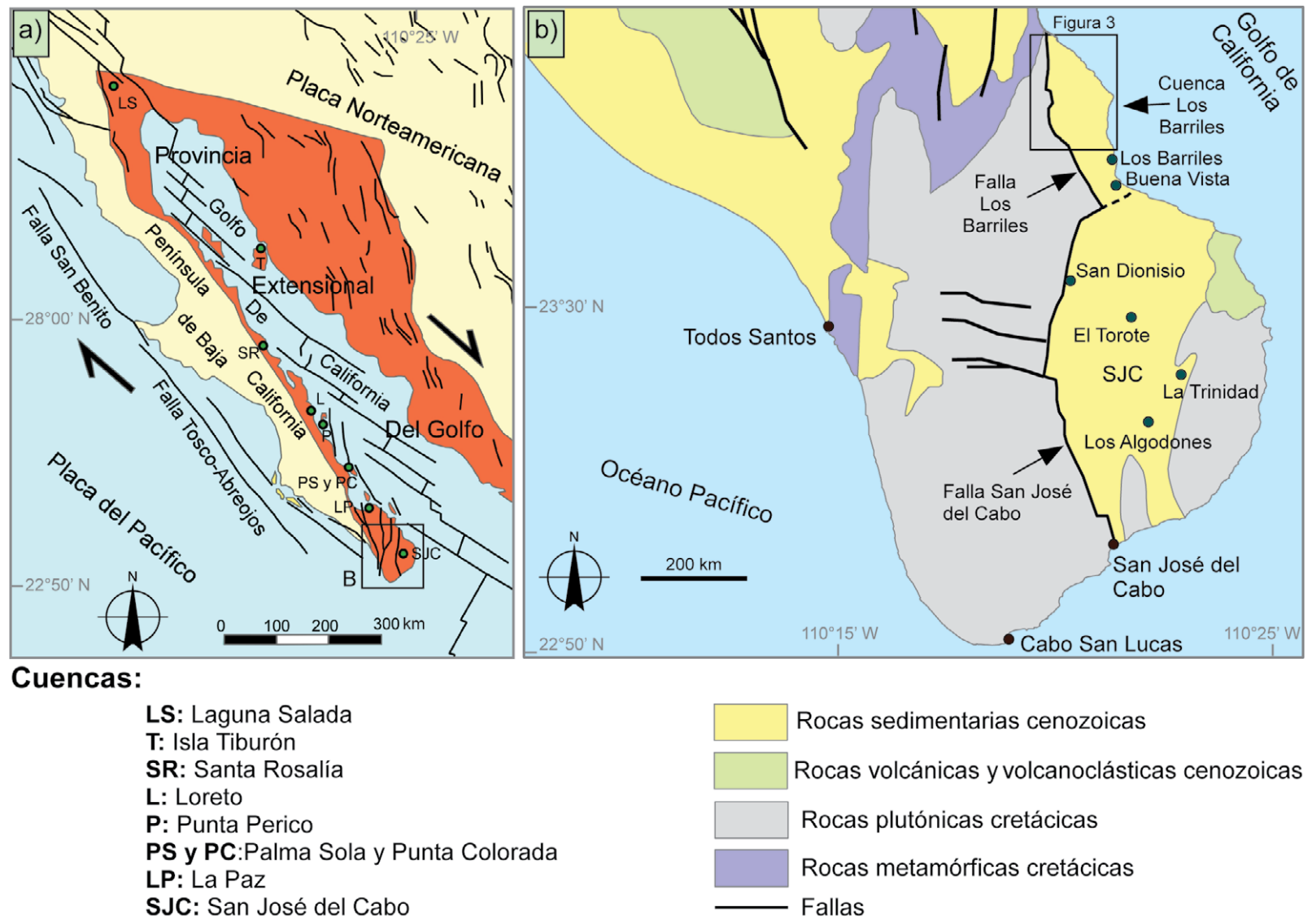

Figura 1. a) El noroeste de México con la localización de cuencas importantes en la porción peninsular de la Provincia Extensional del Golfo (en marrón) (Modificado de Stock y Hodges, 1989). b) Porción sur de la península con la cuenca San José del Cabo (SJC). Modificado de Pérez-Venzor (2013). El recuadro corresponde al área de estudio.

que este medio graben comparte algunas unidades estratigráficas con la cuenca San José de Cabo (Figuras 1 y 2). Cabe mencionar que algunos autores recientes han utilizado el nombre El Cardonal para la cuenca Los Barriles (Pérez-Venzor et al., 2014; Santisteban-Mendívil, 2015).

Las primeras investigaciones (Geoffroy y Pronost, 2010; Masini et al., 2010) se enfocaron en aspectos estructurales de la cuenca Los Barriles y solamente mencionaron la presencia de algunas unidades estratigráficas ya establecidas en la cuenca San José del Cabo. Por lo tanto, su interpretación del desarrollo geológico de la cuenca no tomó en cuenta la estratigrafía. El objetivo de la presente investigación es la descripción de la evolución geológica, con base en el estudio detallado de su relleno. La interpretación de la evolución geológica de la cuenca Los Bariles aporta nuevo conocimiento sobre el inicio de la extensión en la parte sur del golfo de California.

\section{GOLFO DE CALIFORNIA}

El golfo de California (Figura 1) forma parte del límite oblicuodivergente entre las placas Norteamérica y Pacífico (Atwater, 1970; Stock y Hodges, 1989). La mayor parte del movimiento de las placas tiene lugar en el sistema central con núcleos de dispersión cortos conectados por fallas transformantes (DeMets, 1995; Plattner et al., 2007). El fallamiento extensional en la región inició en el Mioceno medio, aproximadamente entre 15 y $14 \mathrm{Ma}$ (Contreras-Pérez et al., 2012; Sutherland et al., 2012) y, posiblemente, incluso antes de que terminara el vulcanismo relacionado con la subducción (Duque-
Trujillo et al., 2015). Para el lapso entre 15 y 6 Ma la configuración del límite de placas está en debate. El modelo tradicional contempla que desde el Mioceno medio se dio una extensión ortogonal (este-oeste) en la Provincia Extensional del Golfo (Stock y Hodges, 1989; Zanchi, 1994; Umhoefer et al., 2002); posteriormente, desde el Plioceno, el fallamiento es de carácter transtensional. Más recientemente, algunos autores han propuesto que el fallamiento derecho oblicuo ha ocurrido desde 14 - $12 \mathrm{Ma}$, sin una etapa de extensión ortogonal (Gans, 1997; Fletcher et al., 2007; Sutherland et al., 2012; Weber, 2012; Bennett y Oskin, 2014). Desde aproximadamente $6 \mathrm{Ma}$ el desplazamiento entre las placas de Norte América y del Pacífico se ha concentrado en la parte central del golfo con la formación de los diferentes núcleos de dispersión (DeMets, 1995; Umhoefer, 2011).

En la Provincia Extensional del Golfo se originaron múltiples cuencas con estructura de graben y medios graben desde finales del Mioceno medio (Martín-Barajas, 2000; Contreras-Pérez et al., 2012; Sutherland et al., 2012). En la porción peninsular de esta provincia existe una serie de cuencas marginales levantadas, las cuales se formaron desde el Mioceno tardío, incluyendo las cuencas de Laguna Salada (Martín-Barajas et al., 2001), Santa Rosalía (Wilson y Rocha, 1955; Holt et al., 2000), Loreto (Zanchi, 1994; Dorsey y Umhoefer, 2000; Umhoefer et al., 2002), Punta Colorada (Umhoefer et al., 2007) y San José del Cabo (Martínez-Gutiérrez y Sethi, 1997; Fletcher et al., 2000; Busch et al., 2011; Arreguín-Rodríguez y Schwennicke, 2013) (Figura 1). Cada una de estas cuencas presenta su propio desarrollo lo que limita la correlación de eventos geológicos. Los primeros depósitos, generalmente, son de carácter aluvial (Martínez-Gutiérrez y Sethi, 1997; 


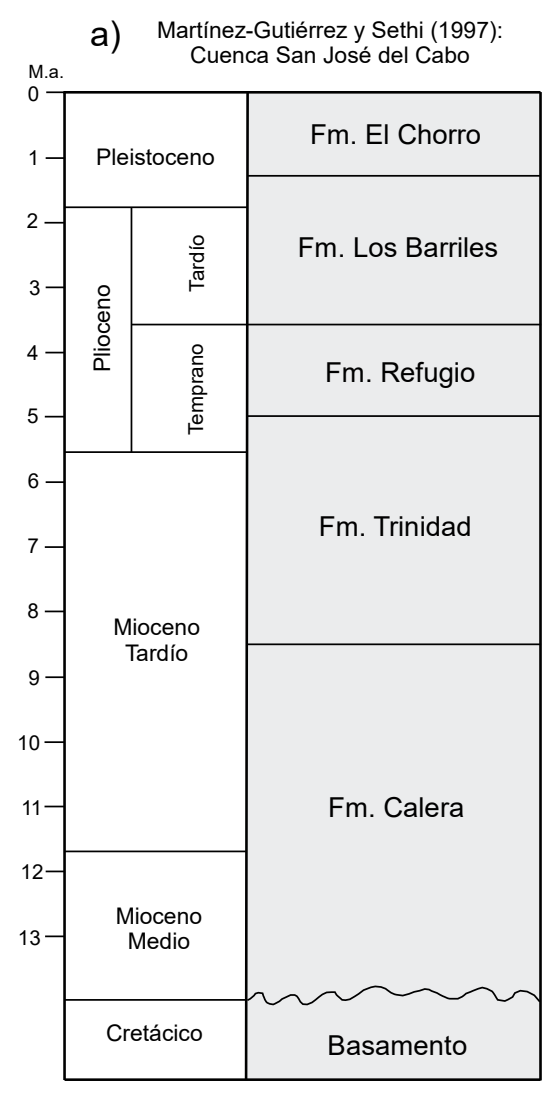

b) Arreguín-Rodríguez y Schwennicke (2013): Margen occidental de la cuenca San José del Cabo

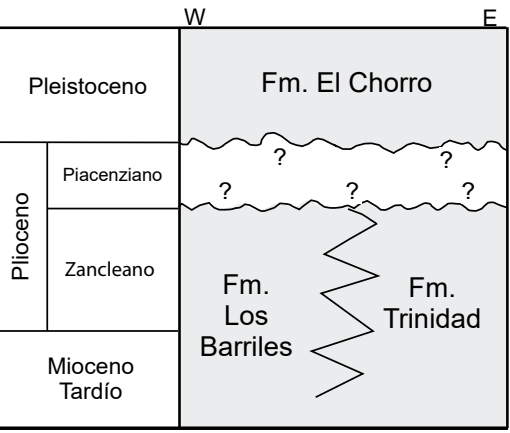

Este trabajo:
d) Cuenca Los Barriles

Este trabajo:

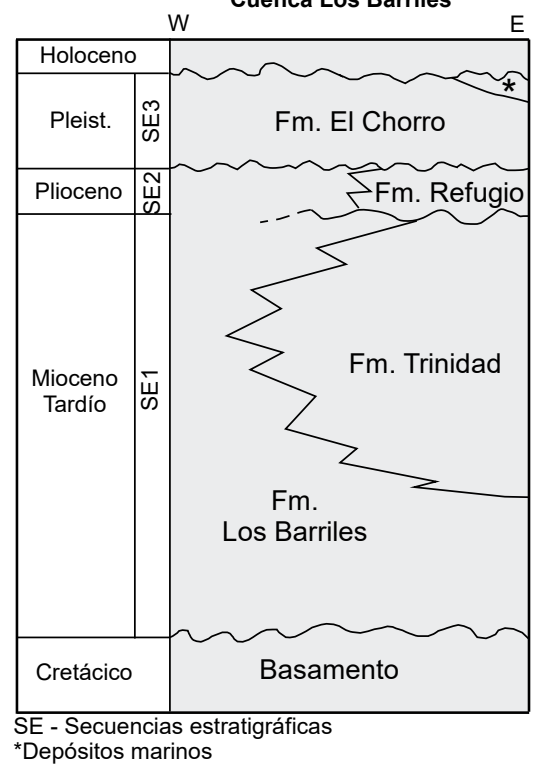

C) Bot et al. (2016):

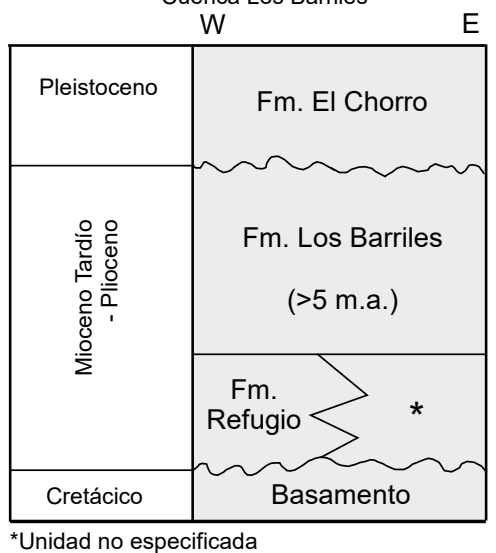

Depósitos marinos

Figura 2. Propuestas estratigráficas por diferentes autores: a) Estratigrafía en la cuenca San José del Cabo (Martínez-Gutiérrez y Sethi, 1997). b) Estratigrafía en el margen occidental de la cuenca San José del Cabo (Arreguín-Rodríguez y Schwennicke, 2013). c) Estratigrafía en la cuenca Los Barriles (basado en la fig. 4 de Bot et al., 2016). d) Estratigrafía en la cuenca Los Barriles propuesta en el presente estudio.

Dorsey y Umhoefer, 2000; Dorsey et al., 2001; Miranda-Avilés et al., 2005; McTeague, 2006; Umhoefer et al., 2007) y localmente ocurren evaporitas (Wilson y Rocha, 1955; Miller y Lizarralde, 2013). En una siguiente etapa, entre el Mioceno tardío y Plioceno, se establecieron condiciones marinas costeras hasta batiales (Martínez-Gutiérrez y Sethi, 1997; Dorsey y Umhoefer, 2000; Dorsey et al., 2001; Carreño y Smith, 2007; Umhoefer et al., 2007). En el Plioceno ocurrió un levantamiento tectónico de varias de estas cuencas, probablemente debido a la reconfiguración tectónica de los segmentos del rift (Dorsey et al., 2001; Umhoefer et al., 2007).

\section{CUENCAS SAN JOSÉ DEL CABO Y LOS BARRILES}

La cuenca San José del Cabo (Figura 1) consiste en un medio graben. Su formación inició aproximadamente entre 12 y $10 \mathrm{Ma}$ (Martínez-Gutiérrez y Sethi, 1997; Fletcher et al., 2000). Las fallas más antiguas están sepultadas en la parte central de la cuenca y desde el Plioceno la estructura marginal es la falla lístrica San José del Cabo (Busch et al., 2011; Arreguín-Rodríguez y Schwennicke, 2013). Recientemente Bot el al. (2016) propusieron que la falla San José del Cabo es una falla de despegue formada desde el Mioceno medio, 
interpretación que contrasta con la de los autores anteriores. Las principales unidades estratigráficas de la cuenca fueron formalmente establecidas por Martínez-Gutiérrez y Sethi (1997, Figura 2a). A lo largo de su margen oriental existen relaciones estratigráficas complejas donde se interdigitan diversas facies, interpretadas como abanicos deltaicos (Schwennicke y Umhoefer, 2008; Schwennicke et al., 2015). Por otra parte, Arreguín-Rodríguez y Schwennicke (2013) aclararon las relaciones estratigráficas en el margen occidental en donde reconocieron dos secuencias estratigráficas separadas por una discordancia angular: la inferior está compuesta por las formaciones Los Barriles (fluvial) y Trinidad (marino), interdigitadas entre sí y por lo tanto contemporáneas, con una edad pliocénica; la secuencia superior corresponde a la Formación El Chorro (fluvial) con una edad probable de Plioceno tardío o Pleistoceno temprano a Pleistoceno (Figura 2b). La rotación de la Formación El Chorro y el aumento de su espesor hacia la falla evidencia que la falla San José del Cabo estuvo activa hasta el Pleistoceno (Arreguín-Rodríguez y Schwennicke, 2013). Sin embargo, a pesar de que en la cuenca San José del Cabo ya existe bastante información cartográfica y estratigráfica (Pantoja-Alor y Carrillo-Bravo, 1966; McCloy, 1984; Martínez-Gutiérrez y Sethi, 1997; McTeague, 2006; Busch et al., 2011; Arreguín-Rodríguez y Schwennicke, 2013), poco conocimiento se tiene del área al norte de la misma (Figura 1).

La cartografía de la región de Los Barriles fue levantada como una carta geológico-minera a escala 1:250000 por el Servicio Geológico Mexicano (Maraver-Romero et al., 2002), donde se muestran los rasgos geológicos de manera general. Bravo-Pérez (2002) estudió la falla San José del Cabo e interpretó la estructura marginal en la cuenca Los Barriles como su extensión norte. Geoffroy y Pronost (2010) reconocieron el carácter de medio graben del área al noroeste de Los Barriles e interpretaron que la falla marginal es lístrica y de despegue, independiente de la falla San José del Cabo y generada en el Plioceno tardío a Pleistoceno temprano, durante la apertura del golfo de California. Más recientemente, Bot et al. (2016) argumentaron que la falla marginal de la cuenca Los Barriles fue originada posteriormente a la falla San José del Cabo y, por lo tanto, consideraron la región al noroeste de Los Barriles como una cuenca independiente. Sin embargo, Geoffroy y Pronost (2010) y Bot et al. (2016) no incluyeron una descripción estratigráfica del relleno sedimentario de esta cuenca, aunque relacionaron las unidades expuestas con las formaciones Los Barriles, Refugio y El Chorro, descritas anteriormente en la cuenca San José del Cabo (Martínez-Gutiérrez y Sethi, 1997). Según Bot et al. (2016; figura 4), en el bloque de techo, el basamento está cubierto por la Formación Refugio y, a su vez, ésta subyace a la Formación Los Barriles. Ambas formaciones son clasificadas por estos autores como unidades "sin-rift", cubiertas discordantemente por la Formación El Chorro (post-rift). Por su parte, Masini et al. (2010) propusieron una unidad estratigráfica nueva sin proporcionar descripciones de la misma. Lo anterior revela discrepancias en la interpretación tectónica de la cuenca Los Barriles y su relación con la cuenca San José del Cabo; además, las investigaciones previas no ofrecen descripciones estratigráficas detalladas de ésta.

\section{METODOLOGÍA}

Elaboramos una cartografía geológica detallada del área mostrada en la Figura 3, que corresponde a la parte central y norte de la cuenca Los Barriles (Figura 1). Adicionalmente, en la región sur se hizo un reconocimiento geológico general (Figura 1). En el área de estudio se levantaron 12 columnas estratigráficas (Figura 3: localidades 16, 18, $19,20,24,31,32,63,38,94,106$ y 118 ) para documentar cambios de litofacies y relaciones estratigráficas entre las unidades litoestratigráficas reconocidas (Santisteban-Mendívil, 2015). En la Formación Los Barriles se midieron clastos imbricados, cuya posición original fue restaurada utilizando el programa Stereonet. Se obtuvieron muestras petrográficas representativas $\mathrm{y} \sim 100$ muestras para análisis micropaleontológico. En laboratorio las láminas micropaleontológicas fueron elaboradas mediante la técnica simple smear slide (Bown y Young, 1999; Andruleit et al., 2000), con el fin de identificar nanofósiles calcáreos y fechar bioestratigráficamente las rocas de la Formación Trinidad. En seis muestras (Figura 3: localidades 28, 32, 62, 63, 70 y 151) se encontraron nanofósiles calcáreos que permitieron la determinación de una edad bioestratigráfica.

\section{ESTRUCTURA DE LA CUENCA LOS BARRILES}

La cuenca Los Barriles estructuralmente es un medio graben, limitado en su lado oeste por el sistema de fallas Los Barriles (Figuras 1 y 3). El bloque de piso está conformado por el basamento cristalino de la sierra La Gata, formando un relieve elevado. La cartografía levantada confirma que el sistema de fallas marginales Los Barriles, no es la continuación de la falla San José del Cabo, como lo interpretaron algunos autores (Fletcher y Munguía, 2000; Fletcher et al., 2000; Busch et al., 2011), sino un sistema independiente. Lo anterior concuerda con Maraver-Romero et al. (2002) y Bot et al. (2016).

A lo largo del sistema de fallas Los Barriles existen varios segmentos de falla, los cuales presentan rumbos distintos (Figura 3: segmentos A - E). En el sur (Figura 3: localidad 201) las capas del bloque de techo (Formación Los Barriles) están rotadas y por lo tanto la falla (128/60 NE) ha sido interpretada por Geoffroy y Pronost (2010) como de despegue. En la parte central de la cuenca, a lo largo de la falla maestra expuesta (localidad 119: 185/50 NE, localidad 125: 158/40 NE), el bloque de techo (formaciones Los Barriles y El Chorro) no presenta rotación (Figura 4). En la parte norte de la cuenca, la falla maestra está cubierta por la Formación El Chorro. Interpretamos estas variaciones como diferentes niveles de erosión a lo largo de un sistema básicamente lístrico (Geoffroy y Pronost, 2010): en el sur aflora un nivel más profundo y, por lo tanto, la falla es de menor ángulo, con capas del bloque de techo más antiguas y rotadas; hacia el norte, el nivel de erosión es superficial, las capas del bloque de techo son más jóvenes y mantienen su disposición original. En tanto que en el lado opuesto de la cuenca, alrededor de Punta Pescadero (Figura 3) existe solamente un pequeño remanente del basamento, cubierto discordantemente por sedimentos del relleno de la cuenca.

En el interior del medio graben se observan abundantes fallas normales que cortan el relleno sedimentario, especialmente en las formaciones Los Barriles y Trinidad. Tienen rumbos paralelos y oblicuos al sistema de fallas marginales y su dirección de inclinación es variable (Figura 5). Algunas de estas fallas evidentemente fueron activas solamente en la etapa temprana de la cuenca, ya que se puede observar que no cortan todos los depósitos (Figura 5d). Como consecuencia del fallamiento, en el sur y centro del área de estudio (Figura 3), las capas de las formaciones Los Barriles y Trinidad se inclinan hacia el noroeste, con un eje de rotación oblicuo a la orientación general del sistema de fallas Los Barriles. Solamente en la parte norte de la cuenca se registra un buzamiento hacia el este y noreste, debido posiblemente a la presencia de una falla en el golfo.

La Formación El Chorro, la cual sobreyace discordantemente las unidades anteriores, no exhibe un fallamiento relevante y por lo tanto preserva su disposición original. 


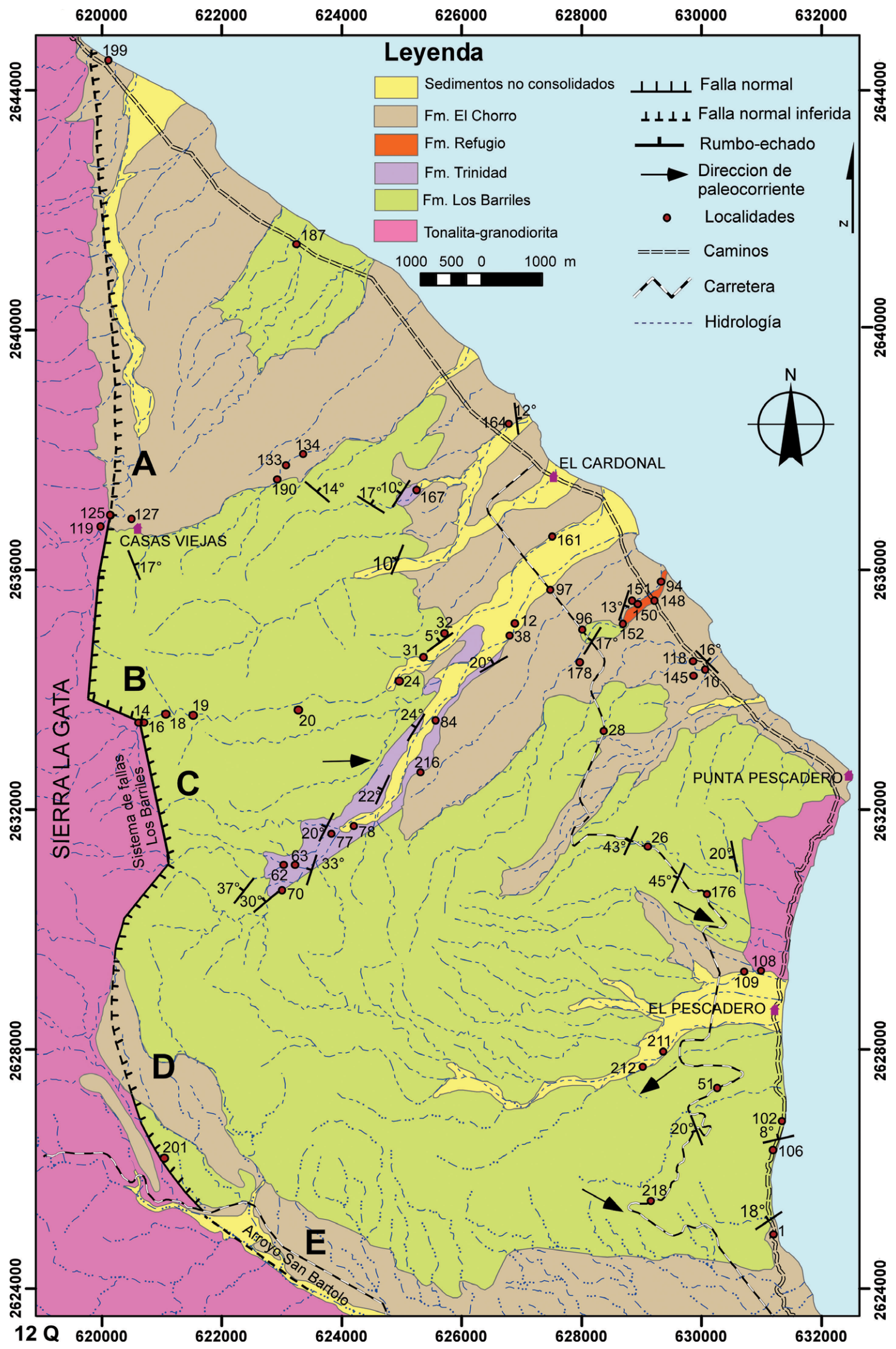

Figura 3. Mapa geológico de la parte centro y norte de la cuenca Los Barriles (Figura 1). Los números (1, 2, 3, etc.) refieren a localidades citadas en el texto; las letras A - E señalan los segmentos del sistema de fallas Los Barriles. 


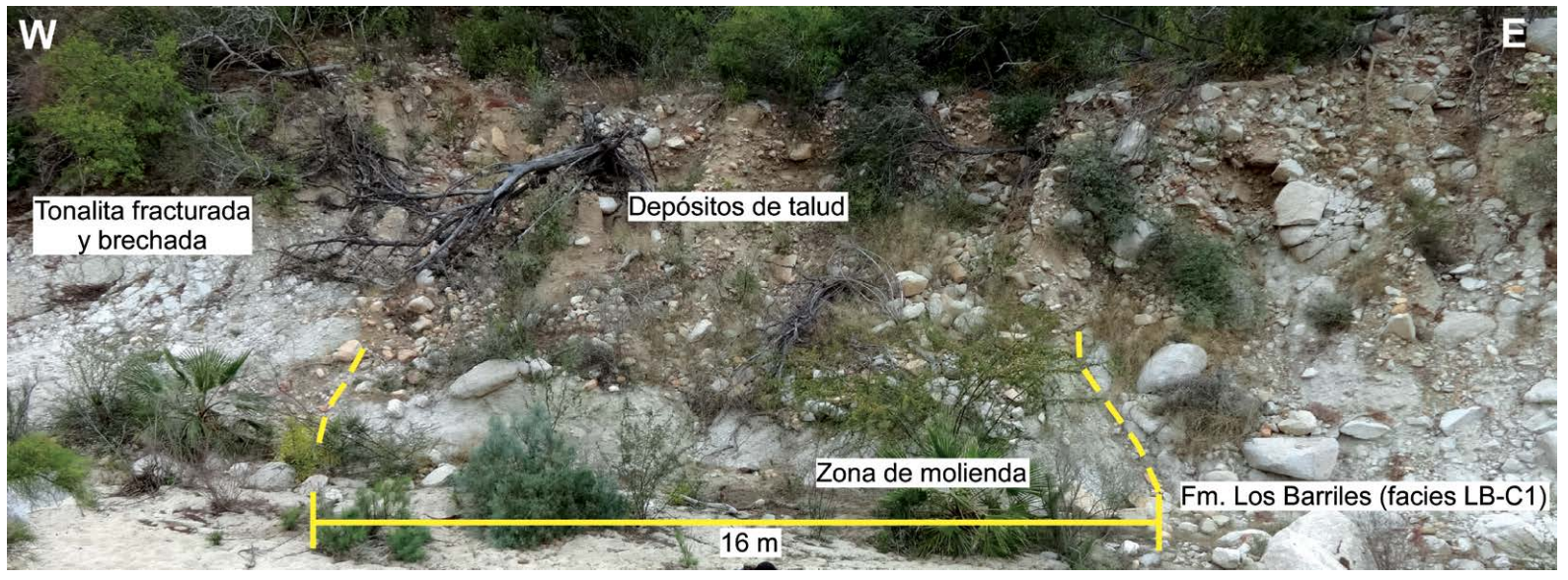

Figura 4. Sistema de fallas Los Barriles, segmento C (Figura 3: localidad 14). En esta localidad la zona de molienda mide $16 \mathrm{~m}$ de ancho.

\section{ESTRATIGRAFÍA}

El bloque de piso de la cuenca Los Barriles está compuesto por rocas intrusivas y metamórficas cretácicas de la sierra La Gata (Schaaf et al., 2000; Pérez-Venzor, 2013; Figura 3). En el presente estudio se reconocen cuatro formaciones preestablecidas en la cuenca San José del Cabo (Pantoja-Alor y Carrillo-Bravo, 1966; Martínez-Gutiérrez y Sethi, 1997), además de los depósitos holocénicos. Las formaciones Los Barriles, Refugio y El Chorro fueron reportadas en el área de estudio por Geoffroy y Pronost (2010) y Masini et al. (2010); no obstante, ellos omiten a la Formación Trinidad, la cual aparentemente fue confundida con la Formación Refugio. Masini et al. (2010) propusieron además una nueva formación (formación Pescadero), pero ésta no fue identificada en el presente estudio y probablemente se refieran a depósitos pertenecientes a la Formación Los Barriles.

\section{Formación Los Barriles}

La Formación Los Barriles, ampliamente expuesta en el centro y sur de la cuenca Los Barriles (Figura 3), se compone de conglomerado $\mathrm{y}$ arenisca. Sobreyace discordantemente a un remanente del basamento alrededor de Punta Pescadero; en el lado oeste está en contacto con el basamento mediante el sistema de fallas Los Barriles. La unidad aflora, con su mayor extensión, en la parte sur de la cuenca donde alcanza un espesor de aproximadamente $700 \mathrm{~m}$. Además, también existen algunos afloramientos en la zona norte de la cuenca. Lateralmente, hacia el centro de la cuenca, se interdigita con la Formación Trinidad.

La Formación Los Barriles se caracteriza por presentar un color gris claro a café (Figura 6). El material clástico que la compone es predominantemente de origen plutónico; sin embargo, una proporción menor está compuesta de clastos de rocas metamórficas que son abundantes en secuencias locales de hasta $30 \mathrm{~m}$ de espesor (Figura 3: localidad 26). Se distinguen varias litofacies en esta formación (Tabla 1). Cerca de la falla marginal predomina brecha y conglomerado grueso con clastos subangulosos y poca organización interna (subfacies LB-B, LB-C1, LB-C-2 y LB-C3). En el área del basamento de Punta Pescadero, los primeros depósitos de la Formación Los Barriles igualmente están caracterizados por clastos subangulosos; mientras que hacia el centro de la cuenca, aumenta el grado de redondez de clastos, la proporción de arenisca conglomerádica así como de arenisca con estratificación paralela y cruzada (subfacies LB-A1 a LB-A4). No obstante, la litofacies de conglomerado (LB-C1 a LB-C4) suele presentarse hasta en los depósitos más distantes donde se intercala con la litofacies de arenisca. Las subfacies LB-A2, LB-A4 y LB-C4 son especialmente comunes en la zona de interdigitación con la Formación Trinidad. La litología de la Formación Los Barriles sugiere que fue depositada en un ambiente de abanico aluvial de gradiente alto, lo cual coincide con la interpretación de Martínez-Gutiérrez y Sethi (1997). Los depósitos se formaron en un abanico dominado por flujos de escombro y corrientes fluviales trenzadas, según la clasificación de Stanistreet y McCarthy (1993). Los datos de paleocorrientes se obtuvieron de clastos imbricados los cuales indican que la mayor parte del aporte se dio del lado oeste de la cuenca y una proporción menor del lado este (Figuras 3 y 7 ). Bot et al. (2016) concluyeron que esta unidad es más antigua que 5 Ma con base en un análisis de nucleidos cosmogénicos en muestras de varias localidades en la Formación Los Barriles (dos de estas en el sureste del área de estudio y una en el arroyo San Bartolo).

La interdigitación con la Formación Trinidad se presenta en afloramientos como cambios transicionales, graduales o abruptos de una unidad a otra (Figura 8); también se observa localmente la Formación Los Barriles en contacto con la Formación Trinidad de manera erosiva. En ambas formaciones las capas tienen la misma disposición.

\section{Formación Trinidad}

La Formación Trinidad aflora en el centro del área de estudio, así como en algunos afloramientos pequeños en el lado este y norte (Figura 3: localidades 118, 145, 133, 134, 161 y 190, entre otras). En el campo se caracteriza por lodolita, limolita y arenisca interestratificadas con colores variables incluyendo beige, grisáceo hasta verdoso (Figura 9). La unidad está interdigitada con la Formación Los Barriles y las secuencias aflorantes de la Formación Trinidad llegan a tener espesores de $150 \mathrm{~m}$ (Figura 3: localidad 77). En general, existen varias litofacies y subfacies (Tabla 2). En partes cercanas a la Formación Los Barriles, la Formación Trinidad está compuesta primordialmente de arenisca fina a gruesa, de composición cuarzo-feldespática con poca continuidad lateral de capas. Se observa estratificación paralela a cruzada y son comunes capas gradadas, producto de flujos gravitacionales. Hacia el centro de la cuenca predomina arenisca fina, lodosa y lodolita arenosa, laminada con abundantes lentes e intercalaciones delgadas de arenisca fina. Además, afloran capas de arenisca fina a gruesa, frecuentemente con base erosiva, gradación e intraclastos lodosos, las cuales fueron formadas por flujos gravitacionales (Figura 10). Así mismo, es posible observar desplome de sedimentos (slumps) y niveles con estratificación convoluta (Figura 10). Es notable la escasa bioturbación en la unidad y la ausencia de fósiles de moluscos.

En suma, las características sedimentológicas señalan que el ambiente de depósito de esta formación varía de aguas someras a más 

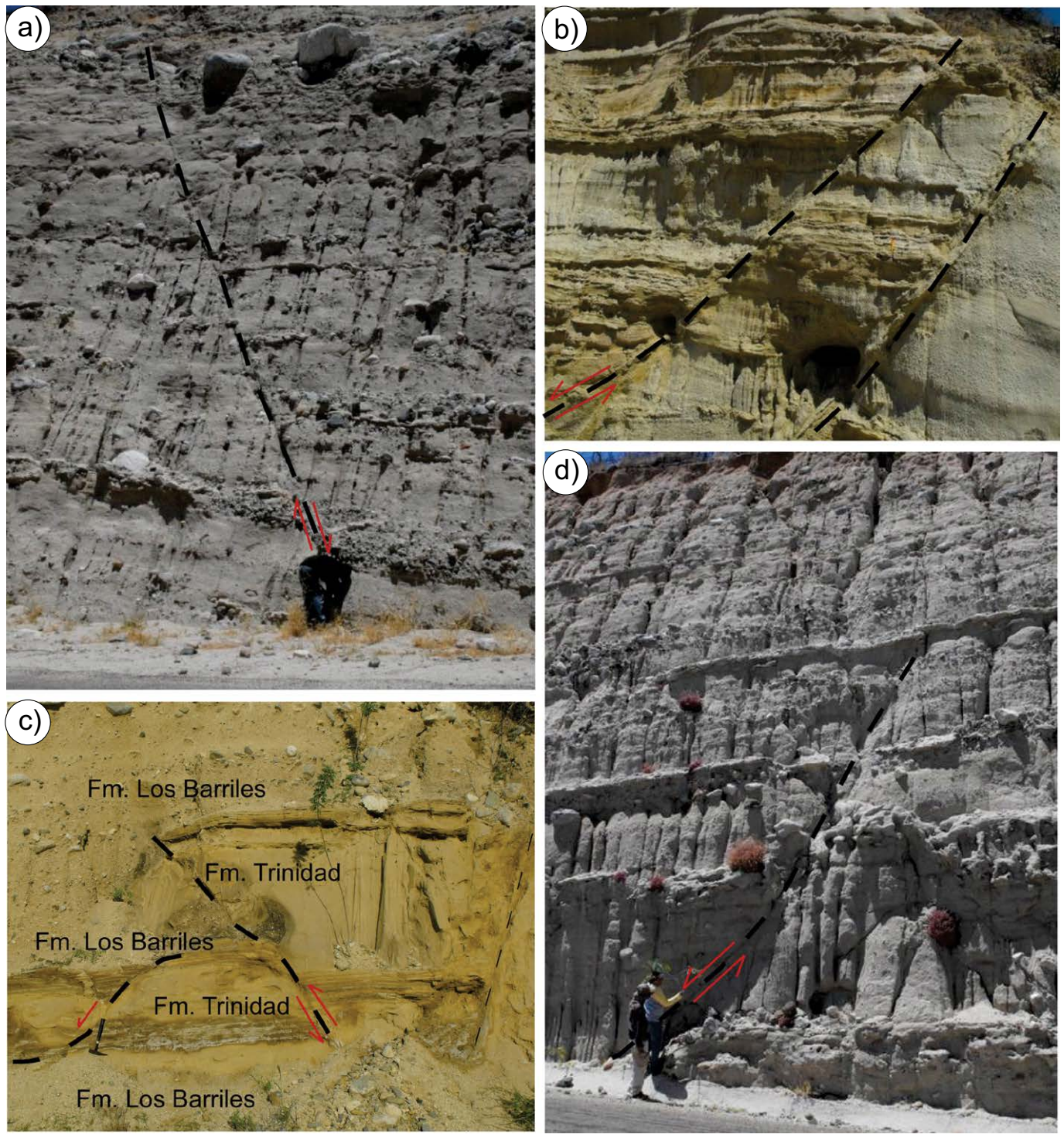

Figura 5. Fallas en la cuenca Los Barriles: a) Falla normal sinsedimentaria en la Formación Los Barriles. La falla se pierde en la parte superior. b) Dos fallas normales en la Formación Trinidad (Figura 3: localidad 84). c) Contacto entre las formaciones Trinidad y Los Barriles con presencia de pequeñas fallas sinsedimentarias (localidad 1). d) Formación Los Barriles con una falla sinsedimentaria la cual se pierde hacia arriba.

profundas por debajo de la influencia del oleaje, con un gradiente suficientemente pronunciado para generar flujos gravitacionales con alta frecuencia. Adicionalmente, la escasez de fósiles e icnofósiles sugiere condiciones variables de salinidad en la cuenca. Sin embargo, la presencia de nanofósiles calcáreos en algunas rocas de la Formación Trinidad en la cuenca Los Barriles refleja condiciones marinas.

En la zona de interdigitación con la Formación Los Barriles y en áreas cercanas, comúnmente se presenta la litofacies arenisca (subfacies T-A1, T-A2 y T-A3; Tabla 2); localmente aparece también la litofacies conglomerado (subfacies T-C1 y T-C2), y en menor proporción la litofacies de alternancia entre lodolita y arenisca (litofacies T-LA). En cambio, en las zonas lejanas, domina la litofacies de alternancia de lodolita y arenisca, mientras que la litofacies arenisca se intercala con capas de menor espesor y la litofacies conglomerado se presenta sólo con la subfacies T-C1. Estos depósitos reflejan un ambiente por debajo del nivel base del oleaje interrumpido esporádicamente por flujos gravitacionales.
Sólo en seis muestras de la Formación Trinidad, en diferentes localidades, pudieron identificarse nanofósiles (Figura 3: localidades $28,32,62,6370$ y 151). Únicamente la muestra 51 de la localidad 32 (Figura 8) presentó un mayor contenido de material fosilífero. Además, ésta última contiene en gran abundancia las especies índice Discoaster berggrenii (Bukry, 1971) y D. quinqueramus (Gartner, 1969; Figura 11). La especie $D$. berggrenii tiene su primera aparición (FAD, por sus siglas en inglés) en la base de la nanozona NN11 (Martini, 1971; Raffi et al., 1998; Young, 1999: figura 8.4), equivalente a la base de la nanozona CNM16 de Backman et al. (2012) y calibrado en $8.20 \mathrm{Ma}$ (Backman et al., 2012). La última aparición (LAD, por sus siglas en inglés) está poco definida. Según Young (1999: figura 8.4) la especie decrece hacia arriba y desaparece en $\sim 6.4 \mathrm{Ma}$, mientras que Wei (2003) señala su LAD alrededor de 6.2 Ma, en NN11b. La especie D. quinqueramus aparece a principios de NN11a y tiene su LAD en la cima de NN11 (Martini, 1971, Young, 1999, Backman et al., 2012), correspondiendo a 5.53 Ma (Backman et al., 2012). Además, en la muestra de la localidad 32 

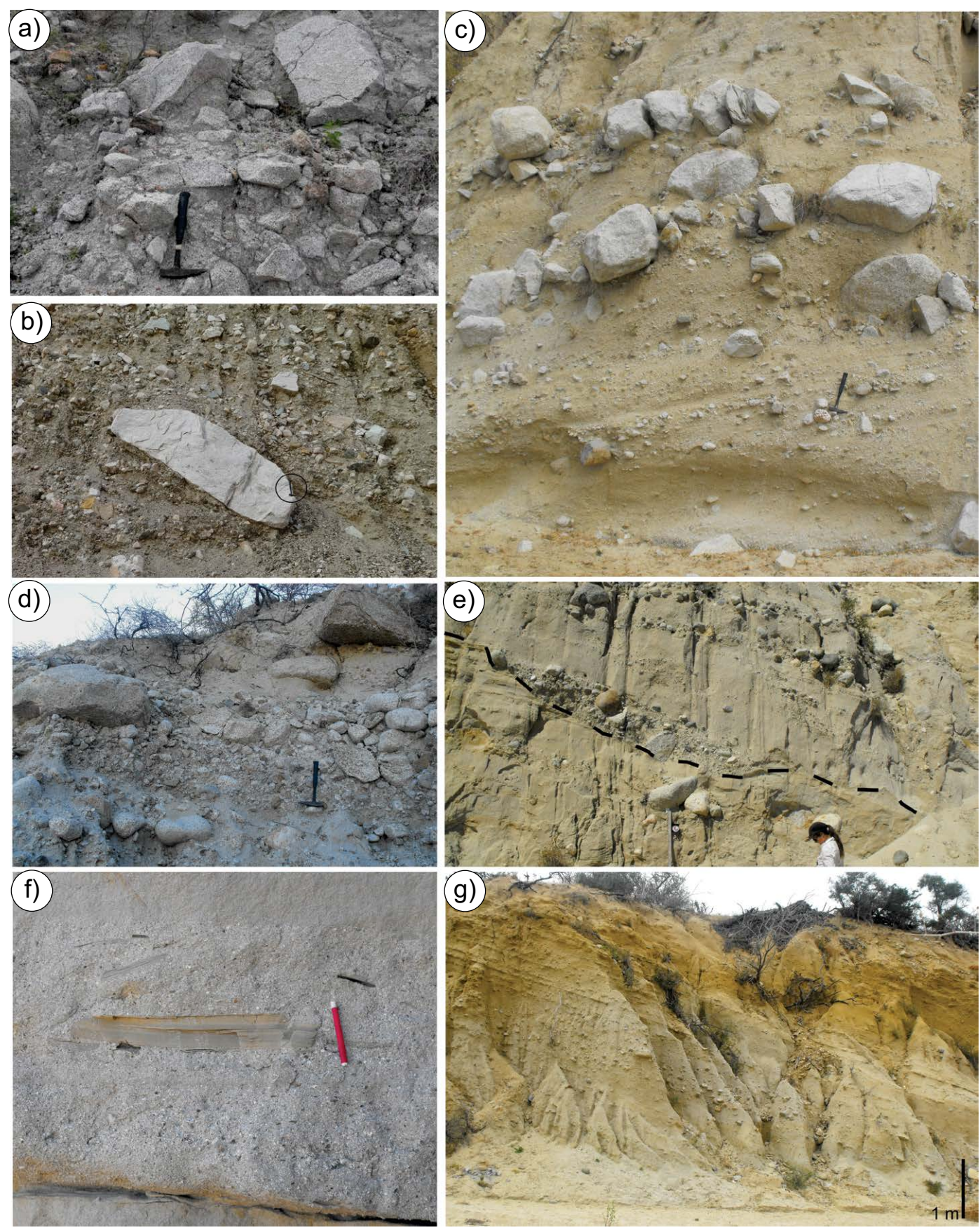

Figura 6. Litofacies en la Formación Los Barriles (Tabla 1): a) Brecha de la facies LB-B (Figura 3: localidad 16). b) Conglomerado de la subfacies LB-C1 (localidad 176). Martillo de geólogo como escala (circulo). c) Arenisca conglomerádica de la subfacies LB-A3 con estratificación difusa y lentes de conglomerado de la subfacies LB-C3 (localidad 127). d) Conglomerado de la facies LB-C2 (localidad 32). e) Arenisca y conglomerado de las subfacies LB-C3 y LB-A1 (localidad 106). f) Capa gradada de la subfacies LB-C4 con un intraclasto de lodolita originario de la Formación Trinidad. La escala mide $13 \mathrm{~cm}$ (localidad 31 ). g) Arenisca conglomerádica estratificada de la subfacies LB-C1 (localidad 187).

se encontraron escasos especímenes de D. blackstockae (Bukry, 1973; Figura 11), de la cual se tienen pocos registros bioestratigráficos (Bukry, 1973; Ellis, 1982; Siesser et al., 1992). Bukry (1973) reportó la especie en toda la NN11. Por otra parte, Siesser et al. (1992) calcularon el FAD de D. blackstockae en 6.3 Ma y su LAD en 5.4 Ma. Sin embargo, Ellis (1982) registró la especie desde finales de su zona WPN 25a (equivalente a NN10). Por lo anterior, consideramos que el D. blackstockae no ofrece mayor precisión en la edad. Otras especies encontradas en las muestras mencionadas son: Coccolithus pelagicus (Paleoceno-NN21; Young, 1999), Calcidiscus leptoporus (NN2-NN21; Young, 1999), C. tropicus (NN4-NN10?; Young, 1999), D. triradiatus (NN9-NN21; Young, 1999), Helicosphaera carteri (NN1-NN21; Young, 1999), Sphenolithus abies (NN7?-NN15; Young, 1999), S. neoabies (NN7-NN15; Okada y Bukry, 1980), y Reticulofenestra pseudoumbilicus (NN4-NN15; Young, 1999).

La presencia de D. quinqueramus indica la zona NN11. La especie D. berggrenii es característica en NN11a y según algunos 
Tabla 1. Litofacies en la Formación Los Barriles (LB): LB-B, brecha; LB-C, conglomerado; LB-A, arenisca. Espesores: capas delgadas, centímetros; capas medianas, decímetros; capas gruesas, mayores de $1 \mathrm{~m}$.

\begin{tabular}{|c|c|c|}
\hline Litofacies/subfacies & Descripción & Interpretación \\
\hline LB-B & $\begin{array}{l}\text { Brecha oligomíctica, generalmente soportada por clastos; clastos an- } \\
\text { gulosos hasta }>1 \mathrm{~m} \text {. El arreglo interno es caótico. Ocurre solamente } \\
\text { muy cerca de la falla marginal. Lateralmente se da la transición a } \\
\text { conglomerado. }\end{array}$ & $\begin{array}{l}\text { Material muy poco retrabajado en la parte cercana del abanico } \\
\text { aluvial o son depósitos de talud producto de caída o avalanchas } \\
\text { de roca (Blair y McPherson, 2008; Sanders, 2010). }\end{array}$ \\
\hline \multirow[t]{4}{*}{ LB-C } & $\begin{array}{l}\text { Capas gruesas de conglomerado fino a grueso soportado por matriz } \\
\text { que varían de caóticas a estratificación paralela y cruzada. Además } \\
\text { presentan gravas residuales de arrastre (lags). }\end{array}$ & $\begin{array}{l}\text { Depósitos de flujos de avenida. La estratificación cruzada sugiere } \\
\text { acreción en barras (Blair y McPherson, 1994; Blair, } 1999 \text { y 2000). } \\
\text { Las gravas residuales (lags) son producto de tamizado (win- } \\
\text { nowing) (Blair y McPherson, 1992). }\end{array}$ \\
\hline & $\begin{array}{l}\text { Capas gruesas de conglomerado grueso soportadas por clastos con } \\
\text { arreglo interno caótico, puede presentar gradación inversa. }\end{array}$ & $\begin{array}{l}\text { Depósitos de flujos de escombro no cohesivos y flujos hipercon- } \\
\text { centrados (Blair y McPherson, 2008). }\end{array}$ \\
\hline & $\begin{array}{l}\text { Lentes medianos de conglomerado soportado por clastos y parcial- } \\
\text { mente por matriz. }\end{array}$ & $\begin{array}{l}\text { Depósitos de flujos de escombro en el abanico aluvial y/o barras } \\
\text { (Blair y McPherson, } 1994 \text { y 2008). }\end{array}$ \\
\hline & $\begin{array}{l}\text { Capas gruesas gradadas que inician con conglomerado y terminan } \\
\text { con arenisca conglomerádica. }\end{array}$ & $\begin{array}{l}\text { Depósitos de flujos de avenida/flujos gravitacionales. La fracción } \\
\text { gruesa se depositó como carga de fondo y la fina, en suspensión } \\
\text { (Blair y McPherson, 1994). }\end{array}$ \\
\hline$L B-A 1$ & $\begin{array}{l}\text { Capas medianas de arenisca conglomerádica homogénea, típica- } \\
\text { mente caótica y localmente, con estratificación difusa. }\end{array}$ & $\begin{array}{l}\text { Depósitos de flujos de avenida o flujos de grano, especialmente } \\
\text { en partes distantes del abanico aluvial (Blair y McPherson, 1994; } \\
\text { Blair, 2000). }\end{array}$ \\
\hline \multirow{4}{*}{ LB-A } & $\begin{array}{l}\text { Capas medianas gradadas, comienzan en la base con conglomerado } \\
\text { o arenisca conglomerádica y finalizan en la cima con arenisca mal } \\
\text { seleccionada. }\end{array}$ & $\begin{array}{l}\text { Durante el depósito se debilita la fuerza de la corriente (Miall, } \\
\text { 1996) o son depósitos de flujos de avenida en abanicos aluviales. } \\
\text { La fracción gruesa es transportada como carga de fondo y la fina } \\
\text { en suspensión. }\end{array}$ \\
\hline & $\begin{array}{l}\text { Capas medianas a gruesas de arenisca mal seleccionada a conglome- } \\
\text { rádica con estratificación paralela, cruzada y cruzada de bajo ángulo. }\end{array}$ & $\begin{array}{l}\text { Cuando presenta estratificación paralela es producto de un régi- } \\
\text { men de flujo superior en flujos de avenida y cuando es estratifica- } \\
\text { ción cruzada por desplazamiento de barras (Blair, 2000). }\end{array}$ \\
\hline & $\begin{array}{l}\text { Capas gruesas de arenisca mal seleccionada a arenisca conglomerá- } \\
\text { dica con estratificación difusa y con bioturbación. }\end{array}$ & $\begin{array}{l}\text { Depósito por flujos de avenida en la parte distante del abanico } \\
\text { aluvial. Posteriormente colonización por organismos. }\end{array}$ \\
\hline & $\begin{array}{l}\text { Capas medianas y lentes de conglomerado intraformacional. Los } \\
\text { intraclastos se componen de lodolita laminada. La subfacies ocurre } \\
\text { solamente cerca de contactos con la Fm. Trinidad. }\end{array}$ & $\begin{array}{l}\text { Los clastos son producto del retrabajamiento fluvial de lodolita } \\
\text { semiconsolidada marina de la Fm. Trinidad, debido a fluctuacio- } \\
\text { nes relativas del nivel del mar. }\end{array}$ \\
\hline
\end{tabular}

autores desaparece dentro de NN11b. Lo anterior sugiere una edad desde la base de NN11a (8.20 Ma) y terminando dentro de NN11b $(\sim 6.20 \mathrm{Ma})$. Cabe mencionar que la especie Amaurolithus primus, la cual por medio de su FAD define el inicio de NN11b no fue encontrada en el presente estudio. De manera más general, lo anterior sugiere para toda la Formación Trinidad una edad de Tortoniano tardío a Messiniano. Al fechar la Formación Trinidad, también queda establecida la edad de los estratos interdigitados de la Formación Los Barriles.

\section{Formación Refugio}

La Formación Refugio aflora en pequeñas áreas en la cuenca Los Barriles, con espesores máximos aproximados de $20 \mathrm{~m}$ (Figura 3: entre las localidades 94 y 152; además, en 164 y 199). Esta formación está caracterizada por arenisca gruesa a conglomerádica, mal clasificada, de color blanco-grisáceo con numerosos fragmentos de bivalvos y gasterópodos, con estratificación paralela a cruzada y abundante bioturbación (Figura 12). Lateralmente, hacia el oeste, se interdigita con la parte superior de la Formación Los Barriles. En áreas más cercanas hacia dicha unidad, la Formación Refugio se compone de arenisca gruesa hasta conglomerádica con un menor porcentaje de fósiles, mientras que en áreas más distantes los depósitos tienden a ser más finos y predomina arenisca fosilífera. La Formación Refugio exhibe tres litofacies de acuerdo a las características litológicas (Tabla 3), las cuales en conjunto apuntan a un ambiente de depósito marino somero de moderada a alta energía con incidencia de oleaje y corrientes.
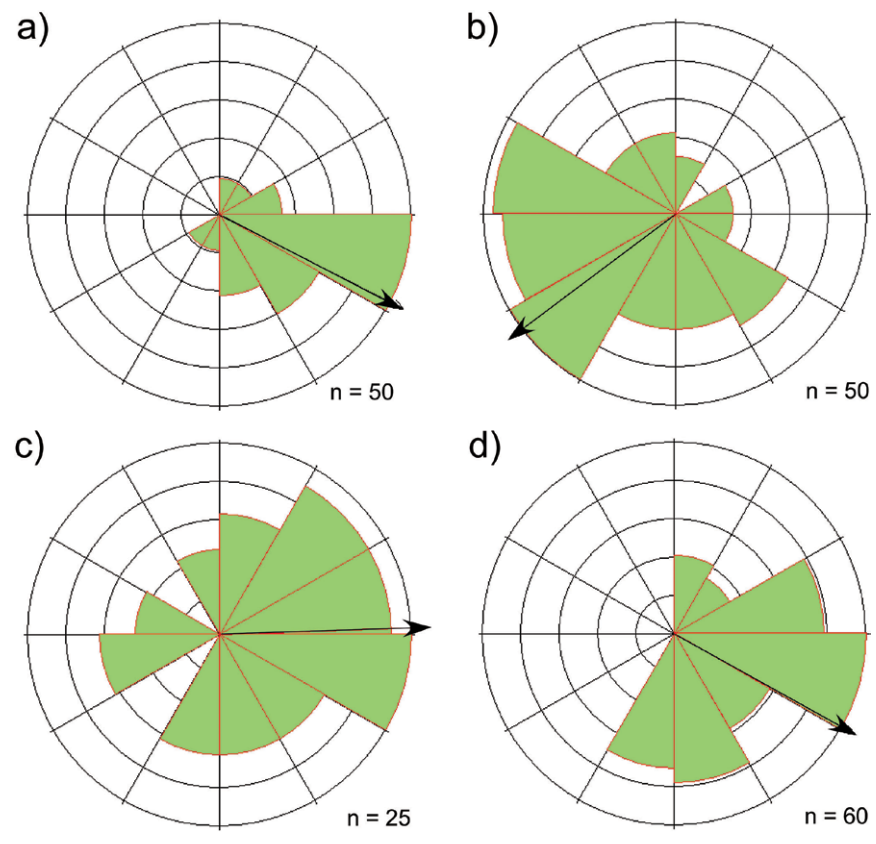

Figura 7. Indicadores de paleocorrientes en la Formación Los Barriles: a) localidad 176, b) localidad 212, c) localidad 216, d) localidad 218 (Figura 3). 


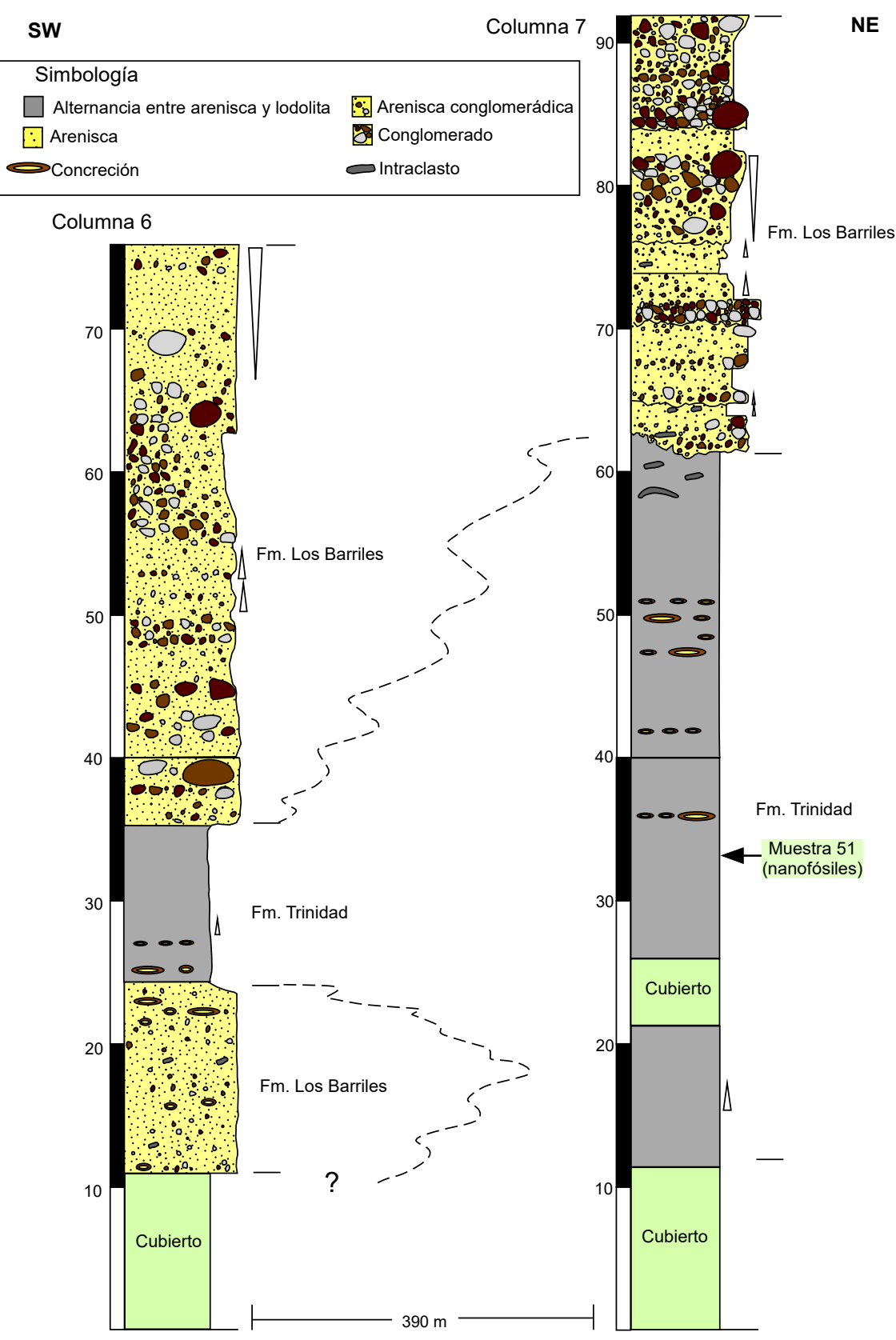

Figura 8. Dos columnas estratigráficas mostrando la interdigitación entre las formaciones Los Barriles y Trinidad (Figura 3: localidades 31 y 32). Se indica la posición de la muestra 51 (ver el texto).

\section{Formación El Chorro}

La Formación El Chorro aflora en la parte centro y norte del área de estudio, aunque en el norte tiene su mayor extensión. El máximo espesor expuesto, de aproximadamente $50 \mathrm{~m}$, aflora en el norte de la cuenca. La unidad se compone de depósitos aluviales que se expresan geomorfológicamente como terrazas. La formación cubre discordantemente las demás unidades estratigráficas (formaciones Los Barriles, Trinidad y Refugio), así como al basamento (Figura 13). De manera general, consiste en conglomerado y arenisca poco litificados con colores de beige a café, con clastos ígneos y metamórficos de la sierra La Gata. Se distinguen varias litofacies: en áreas cercanas a la sierra La Gata está compuesto, principalmente, de conglomerado grueso con clastos mayores a $1 \mathrm{~m}$ y con poca organización interna; en menor proporción, ocurren arenisca conglomerádica y arenisca. Hacia partes distantes de la formación disminuye la presencia de conglomerado grueso; aumenta la proporción de arenisca conglomerádica y de arenisca gruesa y, además, los depósitos están mejor organizados formando capas y lentes. Los depósitos de esta parte exhiben estratificación paralela y cruzada así como también paleocanales; localmente abundan rizolitos y se registran niveles con caliche, indicando pausas en el depósito en un ambiente de abanico aluvial de bajo gradiente.

\section{Depósitos marinos costeros pleistocénicos}

En la costa actual de la parte norte de la cuenca existen depósitos marinos jóvenes compuestos por arenisca conglomerádica y conglomerado con un contenido variable de bioclastos, los cuales sobreyacen 

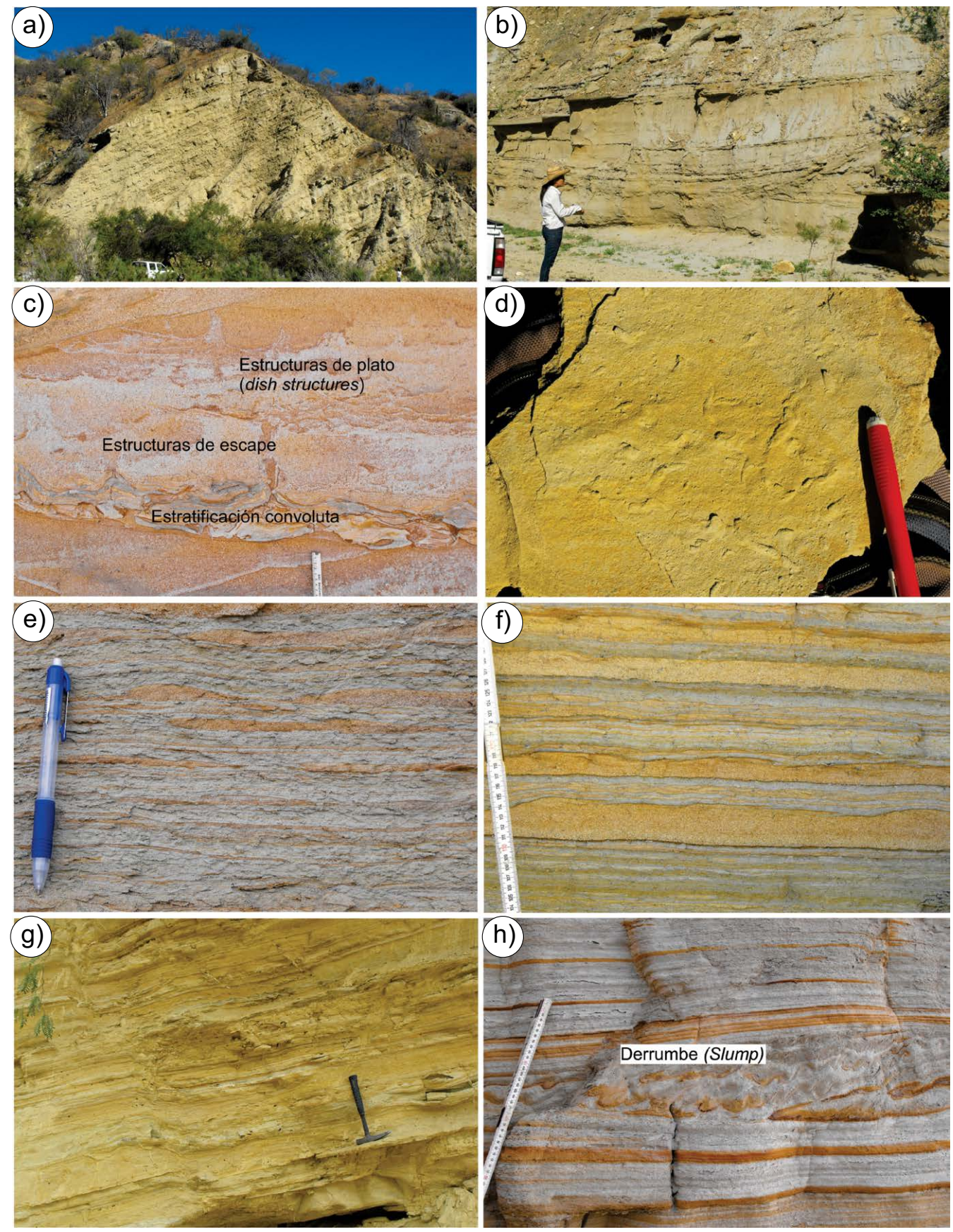

Figura 9. Litofacies en la Formación Trinidad (Tabla 2): a) Vista general en la localidad 63 (Figura 3). b) Arenisca con estratificación paralela y la traza de un paleocanal (localidad 145). c) Arenisca de la subfacies T-A4 (localidad 12). d) Madrigueras mal preservadas en un plano de estratificación (localidad 38). e) Alternancia de arenisca fina, limolita y lodolita de la facies T-LA (localidad 38). f) Alternancia de arenisca, limolita y lodolita de la facies T-LA (localidad 32). g) Alternancia de arenisca, limolita y lodolita de la facies T-LA (localidad 145). h) Derrumbe (slump) en sedimentos distantes de la facies T-LA (localidad 118).

discordantemente a las formaciones Los Barriles, Trinidad y Refugio. Estas "terrazas marinas" (Ortlieb, 1991) tienen poca extensión y alcanzan espesores de hasta $2 \mathrm{~m}$ (Figura 3: localidad 148).

\section{ARQUITECTURA DE FACIES}

El término arquitectura de facies hace referencia a las litofacies formadas en diferentes ambientes de depósito a escalas variadas, a sus relaciones espaciales y a su geometría en la cuenca (Einsele, 2000). Por otro lado, el concepto de las secuencias estratigráficas, desarrollado originalmente en márgenes pasivos (Mitchum et al., 1977), en la actualidad es empleado para todo tipo de cuencas sedimentarias e incluso para cuencas de rift, considerando en estas últimas las variaciones laterales en subsidencia y espacio (Martins-Neto y Catuneanu, 2010; Holz et al., 2014). También ha sido aplicado en la Provincia Extensional del Golfo (Dorsey et al., 1997; Umhoefer et al., 2007).

Los depósitos en el área de estudio fueron divididos en tres secuen- 
Tabla 2. Litofacies en la Formación Trinidad (T): T-LA, alternancia arenisca y lodolita; T-A, arenisca; T-C, conglomerado. Espesores: capas delgadas, centímetros; capas medianas, decímetros; capas gruesas, mayores de $1 \mathrm{~m}$.

\begin{tabular}{|c|c|c|}
\hline Litofacies/subfacies & Descripción & Interpretación \\
\hline T-LA & $\begin{array}{l}\text { Alternancia de capas delgadas (espesores hasta de } 4 \mathrm{~cm} \text { ) de lodolita, } \\
\text { limolita y arenisca. La arenisca forma también lentes pequeños. La- } \\
\text { minación paralela en la lodolita. Laminación paralela y cruzada en } \\
\text { arenisca. Estructuras de crestas y surcos (ridge and furrow structures) } \\
\text { en la base y rizaduras de corriente en la cima de capas de arenisca. } \\
\text { Raramente ocurre estratificación convoluta y presencia de desplo- } \\
\text { mes (slumps). Algunos restos finos de plantas. }\end{array}$ & $\begin{array}{l}\text { La lodolita refleja condiciones tranquilas durante el depósito por } \\
\text { debajo del nivel base del oleaje. La limolita es producto de co- } \\
\text { rrientes débiles. Las capas de arenisca son producto de frecuentes } \\
\text { eventos de corrientes mayores (Collinson et al., 2006). Debido a } \\
\text { inestabilidades ocurren desplomes (slumps) (Postma, 1984). De- } \\
\text { pósito en la parte frontal hasta deltaico distante (Renaut y Gier- } \\
\text { lowski-Kordesch, 2010). }\end{array}$ \\
\hline \multirow[t]{5}{*}{ T-A } & $\begin{array}{l}\text { Capas finas a gruesas de arenisca masiva, varía de fina/media a con- } \\
\text { glomerádica. Escasos intraclastos de lodolita. }\end{array}$ & $\begin{array}{l}\text { Depósito por flujos gravitacionales tales como flujos de granos } \\
\text { (Mulder y Alexander, 2001) o flujos modificados de granos (Car- } \\
\text { ter, 1975). Los intraclastos son de arranque por el flujo. }\end{array}$ \\
\hline & $\begin{array}{l}\text { Capas finas a gruesas con base erosiva. Son gradadas, iniciando en } \\
\text { la base con conglomerado fino o arenisca y terminando en la cima } \\
\text { con arenisca hasta lodolita. Estratificación y laminación difusa a } \\
\text { marcada, y de paralela a cruzada. Raramente contiene intraclastos } \\
\text { de lodolita. }\end{array}$ & $\begin{array}{l}\text { Depósito por flujos gravitacionales concentrados (Mulder y } \\
\text { Alexander, 2001). La laminación y la estratificación paralela su- } \\
\text { gieren flujos de régimen superior, y la estratificación cruzada, } \\
\text { el desplazamiento de formas del lecho. Los intraclastos son de } \\
\text { arranque (Postma et al., 1988). }\end{array}$ \\
\hline & $\begin{array}{l}\text { Capas finas a gruesas de arenisca variando de limosa hasta mal selec- } \\
\text { cionada y conglomerádica. Localmente, presencia de gradación en la } \\
\text { parte basal. Estratificación y laminación paralela y cruzada de bajo } \\
\text { ángulo, raramente estratificación ondulada. Puede tener intraclastos } \\
\text { de lodolita. }\end{array}$ & $\begin{array}{l}\text { Sedimentación bajo condiciones de régimen superior e inferior, } \\
\text { por flujos hiperpícnicos (Mulder et al., 2003). Los intraclastos in- } \\
\text { dican erosión del fondo por el flujo gravitacional (Postma et al., } \\
\text { 1988). }\end{array}$ \\
\hline & $\begin{array}{l}\text { Capas finas a gruesas de arenisca fina hasta conglomerádica las } \\
\text { cuales pueden acuñarse lateralmente, con estratificación paralela y } \\
\text { cruzada. Algunas intercalaciones delgadas e intraclastos de lodolita. } \\
\text { Presencia de estratificación convoluta, algunas estructuras de esca- } \\
\text { pe de fluidos y estructuras de plato (dish structures). Esta subfacies } \\
\text { ocurre solamente en depósitos cercanos de la Formación Trinidad. }\end{array}$ & $\begin{array}{l}\text { Desplazamiento de formas de fondo, con períodos de calma. El } \\
\text { depósito rápido de arena causó el escape de agua, formando di- } \\
\text { versas estructuras (Collinson et al., 2006). }\end{array}$ \\
\hline & $\begin{array}{l}\text { Ocurre en la zona de interdigitación entre las Formaciones Los Ba- } \\
\text { rriles y Trinidad (localidades } 178 \text { y 211). Arenisca fina a gruesa con } \\
\text { marcada laminación paralela, además de estratificación cruzada de } \\
\text { bajo ángulo. Poca bioturbación (Ophiomorpha, Skolithos). Escasas } \\
\text { conchas. }\end{array}$ & Depósito de anteplaya (foreshore) con laminación de playa. \\
\hline \multirow[t]{2}{*}{$\mathrm{T}-\mathrm{C}$} & $\begin{array}{l}\text { Capas medianas y lentes de conglomerado intraformacional. Los in- } \\
\text { traclastos se componen de lodolita laminada y flotan en una matriz } \\
\text { de arenisca mal seleccionada. }\end{array}$ & $\begin{array}{l}\text { Son producto de flujos gravitacionales que erosionaron el fondo } \\
\text { marino y se depositaron rápidamente (Haughton, et al., 2009). }\end{array}$ \\
\hline & $\begin{array}{l}\text { Lentes hasta clastos aislados (pebbles, cobbles) en capas de arenisca. } \\
\text { Esta subfacies ocurre comúnmente cerca de contactos con la Fm. } \\
\text { Los Barriles. }\end{array}$ & $\begin{array}{l}\text { Producto de flujos gravitacionales fuertes, incluyendo flujos de } \\
\text { escombro (Mulder y Alexander, 2001). }\end{array}$ \\
\hline
\end{tabular}

cias estratigráficas separadas por discordancias, las cuales posiblemente obedecen a mecanismos tectónicos y/o eustáticos (Holz et al., 2014). Los sedimentos no consolidados (de aluvión y de playa) no fueron considerados como secuencia estratigráfica debido a que aún están en formación, según la definición original de Mitchum et al. (1977). A continuación, se expondrá la asociación de facies de cada una de las secuencias estratigráficas con sus variaciones laterales y verticales, además de su distribución en la cuenca.

\section{Secuencia estratigráfica 1}

La secuencia estratigráfica 1 está compuesta por las formaciones Los Barriles y Trinidad, las cuales están interdigitadas (Figuras 8 y 14), siendo las unidades sedimentarias más antiguas de la cuenca y consideradas por Geoffroy y Pronost (2010) como "sin-rift". En casi todas las localidades, las capas de la secuencia 1 exhiben un buzamiento hacia el NW. En el área de Punta Pescadero, la Formación Los Barriles sobreyace el basamento y, a su vez, está cubierta por la Formación Trinidad (Figura 3: localidad 10 y 109). El contacto superior de la secuencia 1 es, al parecer, una discordancia angular entre las formaciones Trinidad y Refugio y no fue observado directamente en el campo. Sin embargo, su existencia es inferida ya que en la localidad 151 (Figura 3) los estratos de la Formación Trinidad están basculados $13^{\circ}$ hacia el $\mathrm{NW}$, mientras que a $100 \mathrm{~m}$ aproximadamente (localidad 150) aflora la Formación Refugio con capas horizontales.

La Formación Los Barriles refleja un ambiente de abanico aluvial de alto gradiente. En la porción cercana al basamento predomina conglomerado producto de flujos de escombro; en cambio, hacia la parte distante aumentan los depósitos arenosos de barras así como de flujos de avenida (Tabla 1). En la zona de interdigitación con la Formación Trinidad tiende a dominar la litofacies arenisca. El tipo de abanico aluvial corresponde a abanicos entre los dominados por flujos de escombro y los fluviales trenzados (Stanistreet y McCarthy, 1993).

En la Formación Trinidad es posible observar variaciones de litofacies cercanas a lejanas, las cuales corresponden a ambientes marinos (Tabla 2). En la zona de interdigitación con la Formación Los Barriles y en áreas cercanas predomina arenisca, la litofacies de alternancia de lodolita y arenisca ocurre en menor proporción y la litofacies conglomerado se observa localmente. Estos depósitos son producto de condiciones de aguas relativamente someras, formados por encima del nivel base de oleaje. En cambio, en las zonas distantes domina la 

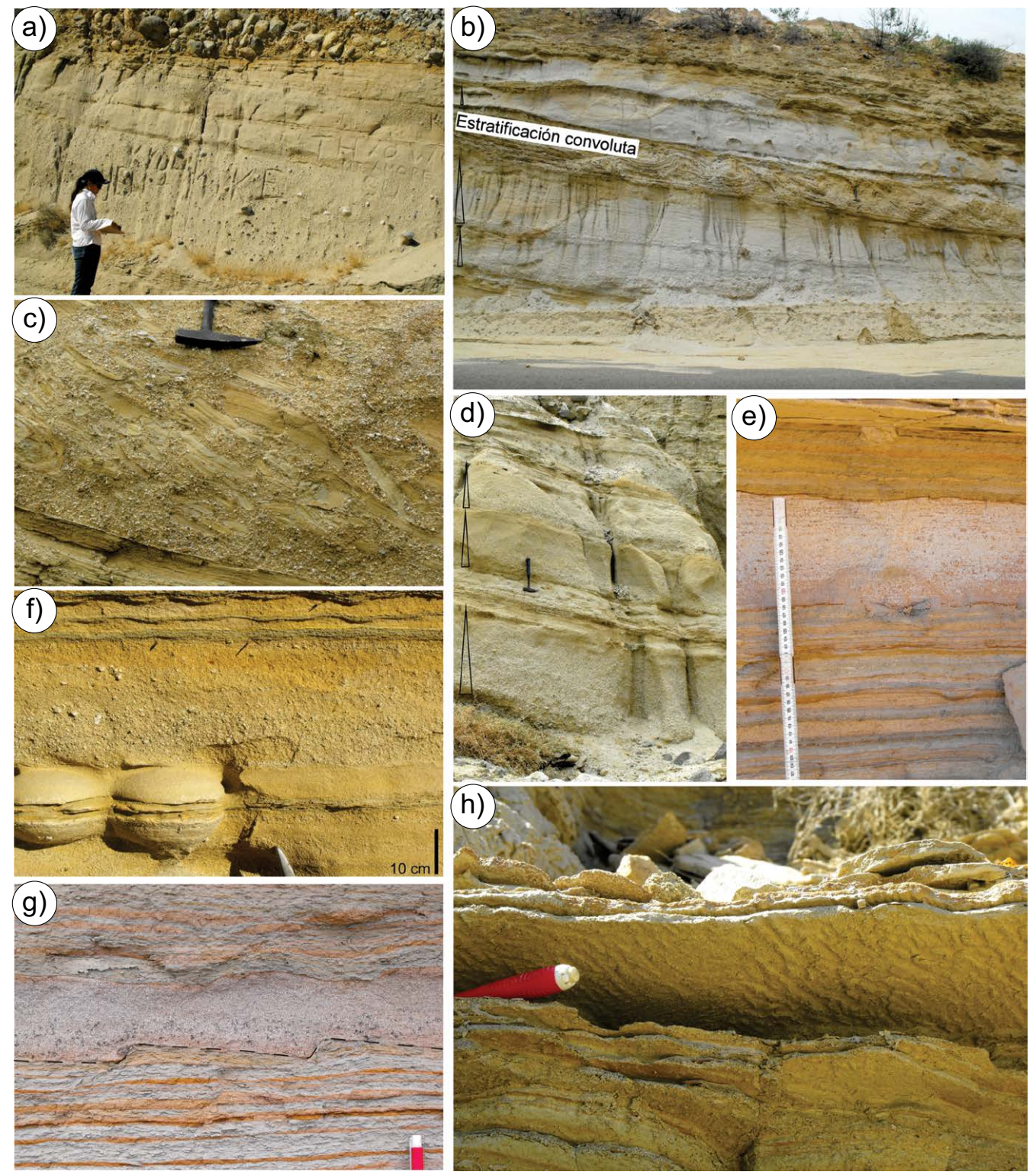

Figura 10. Litofacies en la Formación Trinidad (Tabla 2): a) Arenisca conglomerádica caótica de la subfacies T-C3 y arenisca estratificada, cubiertas por conglomerado de la Formación Los Barriles (Figura 3: localidad 106). b) Capas gruesas de arenisca (color gris claro) de la subfacies T-A3, alternando con lodolita, limolita y arenisca lodosa. Estratificación convoluta (localidad 97). c) Conglomerado intraformacional con clastos de lodolita de la subfacies T-C1 (localidad 32). d) Capas gradadas de la subfacies T-A2 (localidad 102). e) Una capa de arenisca de la subfacies T-A3 intercalada en la facies T-A3 (localidad 32). f) Capa de arenisca conglomerádica con estratificación paralela difusa de la subfacies T-A3 (localidad 12). g) Capa gradada con marcas de corriente en la base de la subfacies T-A2, intercalada en la facies T-LA (localidad 38). h) Estructuras de cresta y surco (ridge and furrow structures) en la base de una capa de arenisca en la facies T-LA (localidad 167).

a)

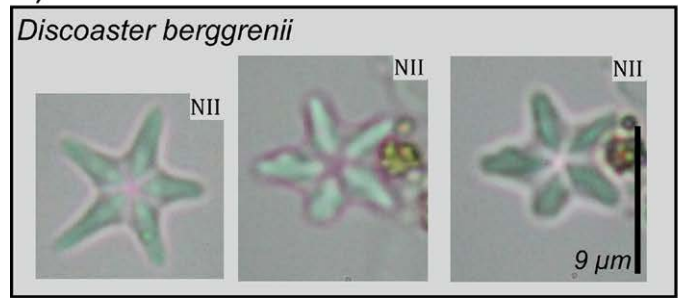

b)

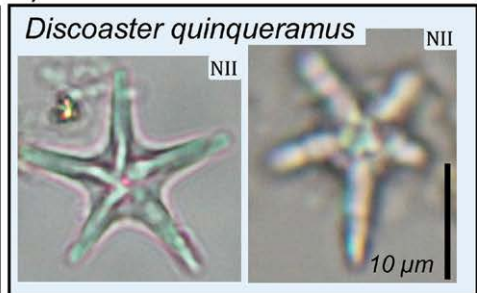

c)

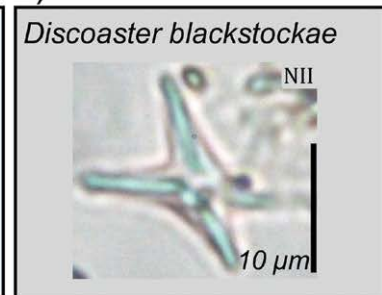

Figura 11. Nanofósiles índice en la Formación Trinidad: a) Discoaster berggrenii, b) D. quinqueramus, c) D. blackstockae. Muestra 51, localidad 32 (Figuras 3 y 8). 

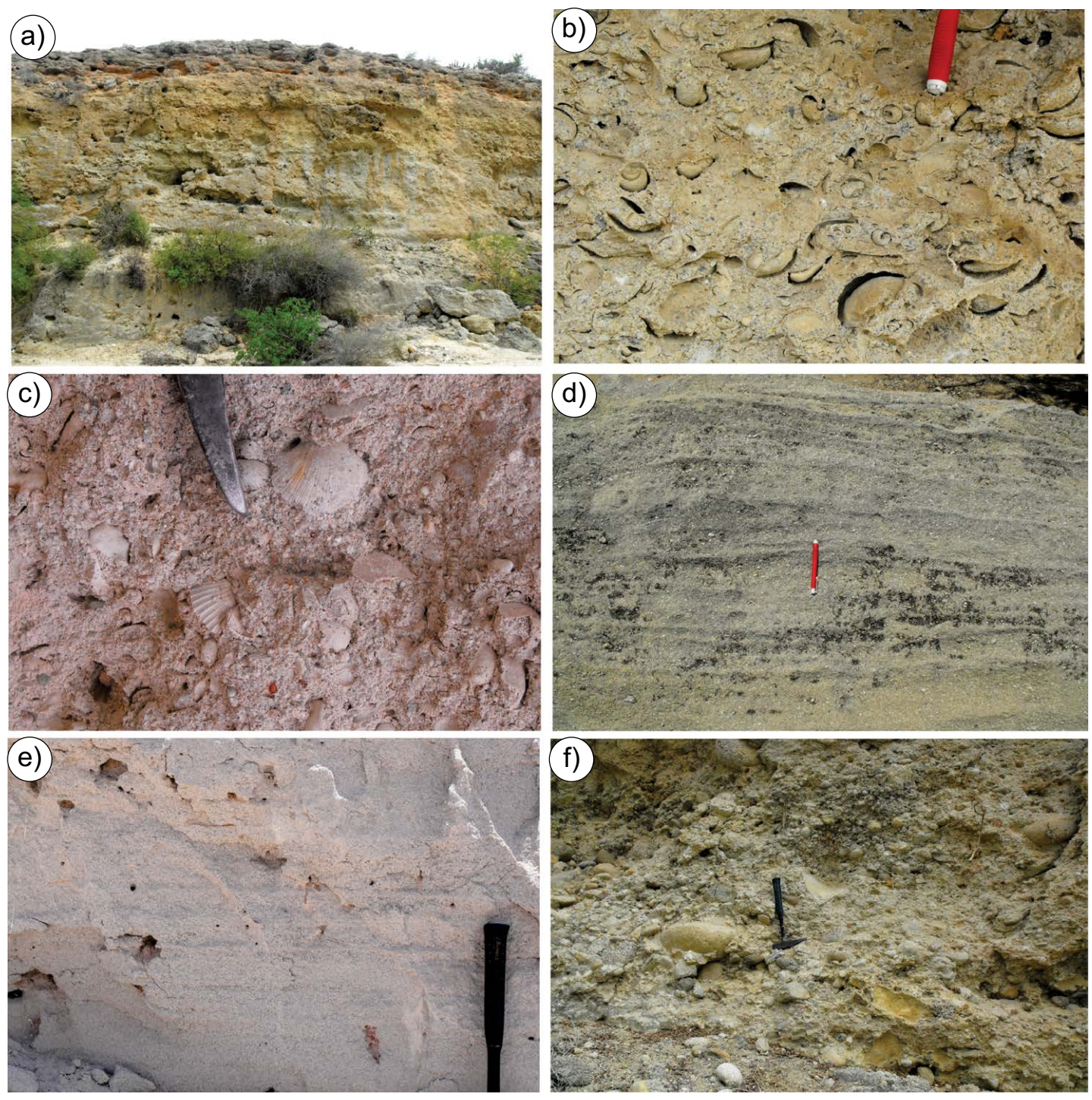

Figura 12. Litofacies en la Formación Refugio (Tabla 3): a) Vista general de la facies R-AF (Figura 3: localidad 94). b) Arenisca coquinoide de la facies R-AF (localidad 150). c) Arenisca conglomerádica coquinoide de la subfacies R-AF2 (localidad 150). d) Arenisca conglomerádica estratificada con pocos bioclastos de la subfacies R-AF1. La escala mide $13 \mathrm{~cm}$ (localidad 164). e) Arenisca con laminación de playa de la facies R-A (localidad 148). f) Paraconglomerado con pocos bioclastos de la facies R-C (localidad 152).

Tabla 3. Litofacies en la Formación Refugio (R): R-AF, arenisca fosilífera; R-C, conglomerado; R-A, arenisca. Espesores: capas delgadas, centímetros; capas medianas, decímetros; capas gruesas, mayores de $1 \mathrm{~m}$.

\begin{tabular}{|c|c|c|c|}
\hline \multicolumn{2}{|c|}{ Litofacies/subfacies } & \multirow{2}{*}{$\begin{array}{l}\text { Descripción } \\
\text { Capas gruesas de arenisca coquinoide mal seleccionada hasta con- } \\
\text { glomerádica. Estratificación ausente o difusa y va desde paralela a } \\
\text { cruzada. La bioturbación es común. El contenido de fósiles varía, } \\
\text { predominando bivalvos y gasterópodos. }\end{array}$} & \multirow{2}{*}{$\begin{array}{l}\text { Interpretación } \\
\text { Ambiente marino somero, depósitos de playa frontal (shoreface) } \\
\text { de alta energía. }\end{array}$} \\
\hline R-AF & $R-A F 1$ & & \\
\hline & \multirow[t]{2}{*}{$R-A F 2$} & $\begin{array}{l}\text { Capas medianas a gruesas de arenisca coquinoide que varía desde } \\
\text { mal seleccionada hasta conglomerádica. Estratificación nula o difusa } \\
\text { y varía de paralela a cruzada. Bioturbación y abundantes moluscos } \\
\text { fósiles. }\end{array}$ & $\begin{array}{l}\text { Ambiente marino somero, depósitos de playa frontal (shoreface) } \\
\text { de alta energía. }\end{array}$ \\
\hline $\mathrm{R}-\mathrm{C}$ & & $\begin{array}{l}\text { Capas medianas y lentes de conglomerado coquinoide soportado } \\
\text { por clastos y localmente por matriz. Es caótico y puede presentar } \\
\text { bioturbación. Escasos fósiles. La litofacies ocurre cerca de los con- } \\
\text { tactos con la Fm. Los Barriles. }\end{array}$ & $\begin{array}{l}\text { Ambiente marino somero, depósitos de playa frontal (shoreface) } \\
\text { de alta energía. Aporte de sedimento grueso al ambiente marino. }\end{array}$ \\
\hline R-A & & $\begin{array}{l}\text { Capa gruesa de arenisca fina a mediana, poco litificada y con lami- } \\
\text { nación paralela (localidad 148), en contacto con la litofacies R-AF. }\end{array}$ & Depósitos de anteplaya (foreshore) con laminación de playa. \\
\hline
\end{tabular}


litofacies de alternancia de lodolita y arenisca, mientras que la litofacies arenisca está presente con menor espesor, lo cual señala un ambiente más profundo y de baja energía, interrumpido esporádicamente por flujos gravitacionales.

La secuencia estratigráfica 1 se depositó en ambientes que abarcan desde abanico aluvial cercano hasta abanico deltaico lejano. En general, los deltas exhiben distintas características que dependen del sistema alimentador, la profundidad del agua en la cuenca, las diferentes maneras de dispersión sedimentaria en la parte frontal del delta y las fluctuaciones del nivel del cuerpo acuático (Postma, 1990 y 1995). El mismo autor divide la parte aérea de los deltas en cuatro tipos, de A a D, de acuerdo al sistema alimentador. El primero se refiere a sistemas aluviales dominados por grava y con un gradiente abrupto, caracterizados por corrientes no confinadas y efímeras, incluyendo flujos de masas, formándose a lo largo de escarpes de falla y en fiordos. La Formación Los Barriles corresponde a la parte aérea de los abanicos deltaicos, sus depósitos son producto de corrientes efímeras y fueron formados mayormente a lo largo de un escarpe de falla (Los Barriles); por lo tanto, se propone que los abanicos deltaicos desarrollados en el área de estudio pertenecen al sistema alimentador tipo A (Postma, 1990).

Los deltas con un sistema alimentador tipo A, a su vez, se dividen en tres: el tipo Hjulström de aguas someras, el clásico tipo Gilbert con capas frontales de crecimiento progresivo y el tipo Gilbert de aguas profundas (Postma, 1990). Éstos pueden formarse en ambientes marinos y lacustres (Colella, 1988; Postma, 1990; Benvenuti, 2003).

El delta tipo Hjulström se desarrolla principalmente en aguas someras y está caracterizado por una pendiente suave en su parte frontal (Postma, 1990). Estos abanicos deltaicos, generalmente, son de alta energía y están influenciados directamente por el oleaje. Debido a lo anterior, sus depósitos suelen presentar icnofósiles tales como Skolithos isp. y Ophiomorpha isp., ambos son elementos de la icnofacies Skolithos (MacEachern et al., 2007). En la secuencia estratigráfica 1 no se observaron depósitos con dichas características. Por otro lado, el clásico tipo Gilbert difiere de los demás por presentar capas superiores (topsets), frontales (foresets) y de fondo (bottomsets) (Colella, 1988). El depósito en la porción superior de las capas frontales está controlado por flujos de masa, deslizamientos, flujos de corriente no confinados y/o retrabajamiento marino; mientras que en la parte frontal y de fondo dominan flujos gravitacionales de masa, flujos hiperpícnicos y, en la parte más distante, procesos de suspensión (Postma, 1990; Falk y Dorsey, 1998; Mulder y Alexander, 2001; Mulder et al., 2003). Si bien en el área de estudio encontramos depósitos similares, no se observaron capas frontales de crecimiento progresivo. Por último, el delta tipo Gilbert de aguas profundas no contiene capas superiores, frontales y de fondo, respectivamente, ya que por la profundidad solo desarrolla una pendiente por debajo de la influencia del oleaje. Por ello, en estos abanicos deltaicos la sedimentación está dominada por procesos de suspensión y transporte gravitacional de masas (Postma, 1990). La presencia de canales en estratos de la Formación Trinidad (Figura 15) podría deberse a una incidencia frecuente de este tipo de eventos. Conforme a lo anterior, los depósitos de aguas profundas estarían dominados por sedimentos lodosos, con intercalaciones de sedimentos arenosos y gravosos producto de flujos gravitacionales. Así, las características de los depósitos de la secuencia estratigráfica 1 en la cuenca Los Barriles coinciden con el abanico delta tipo Gilbert de aguas profundas. La presencia de deltas de aguas profundas sin capas frontales sugiere un desplazamiento relativamente rápido y continuo en el sistema de fallas marginales. Algunos contactos erosivos entre depósitos marinos y fluviales en la zona de interdigitación (Figura 8 y 14b) son, probablemente, producto de fluctuaciones del nivel base (Postma, 1995).

\section{Secuencia estratigráfica 2}

La secuencia estratigráfica 2 está integrada por las formaciones Los Barriles y Refugio (Figura 16). El contacto inferior, como se mencionó anteriormente, corresponde a una discordancia angular entre las for-
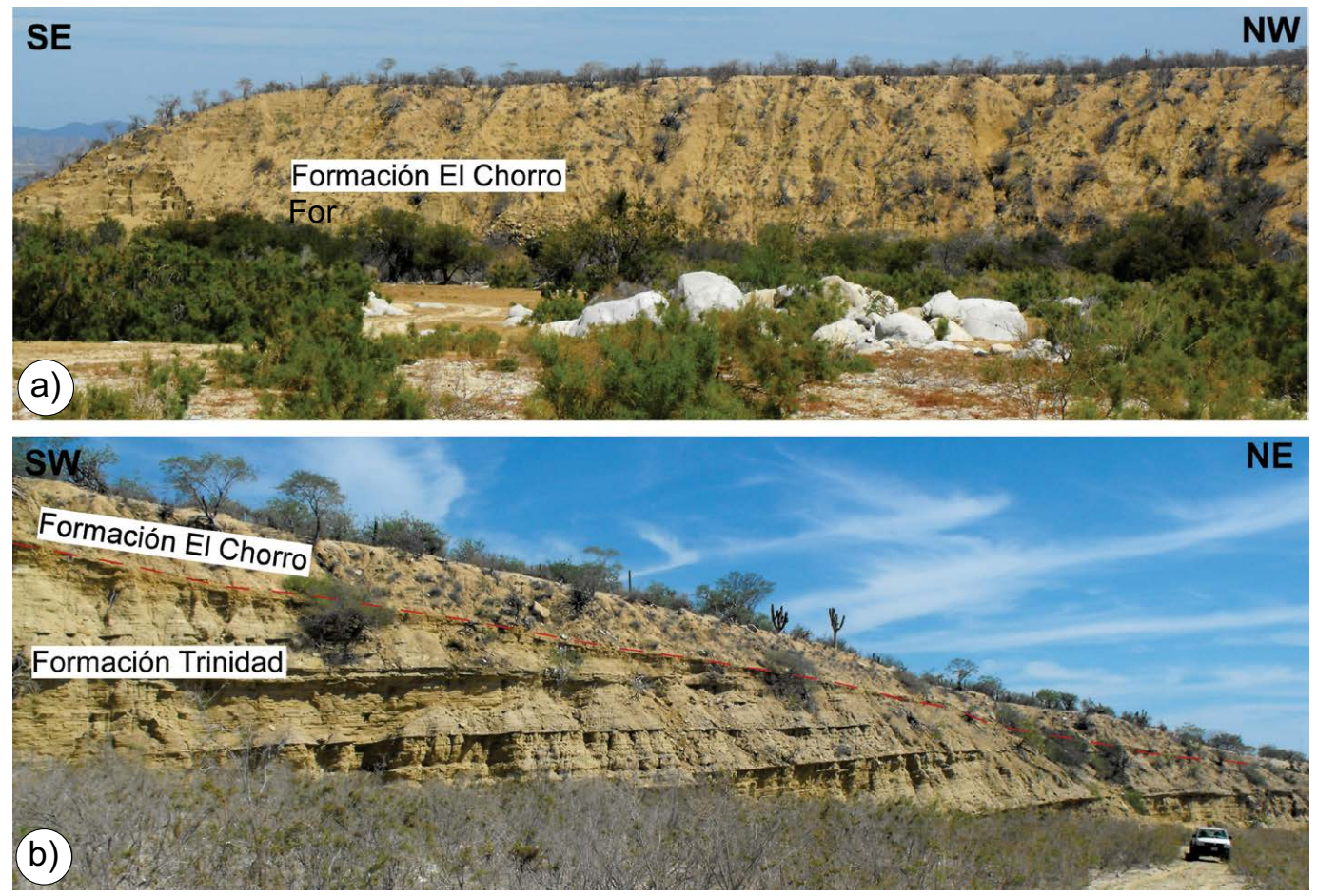

Figura 13. Formación El Chorro: a) En el norte de la cuenca. b) Localidad 161 (Figura 3). 

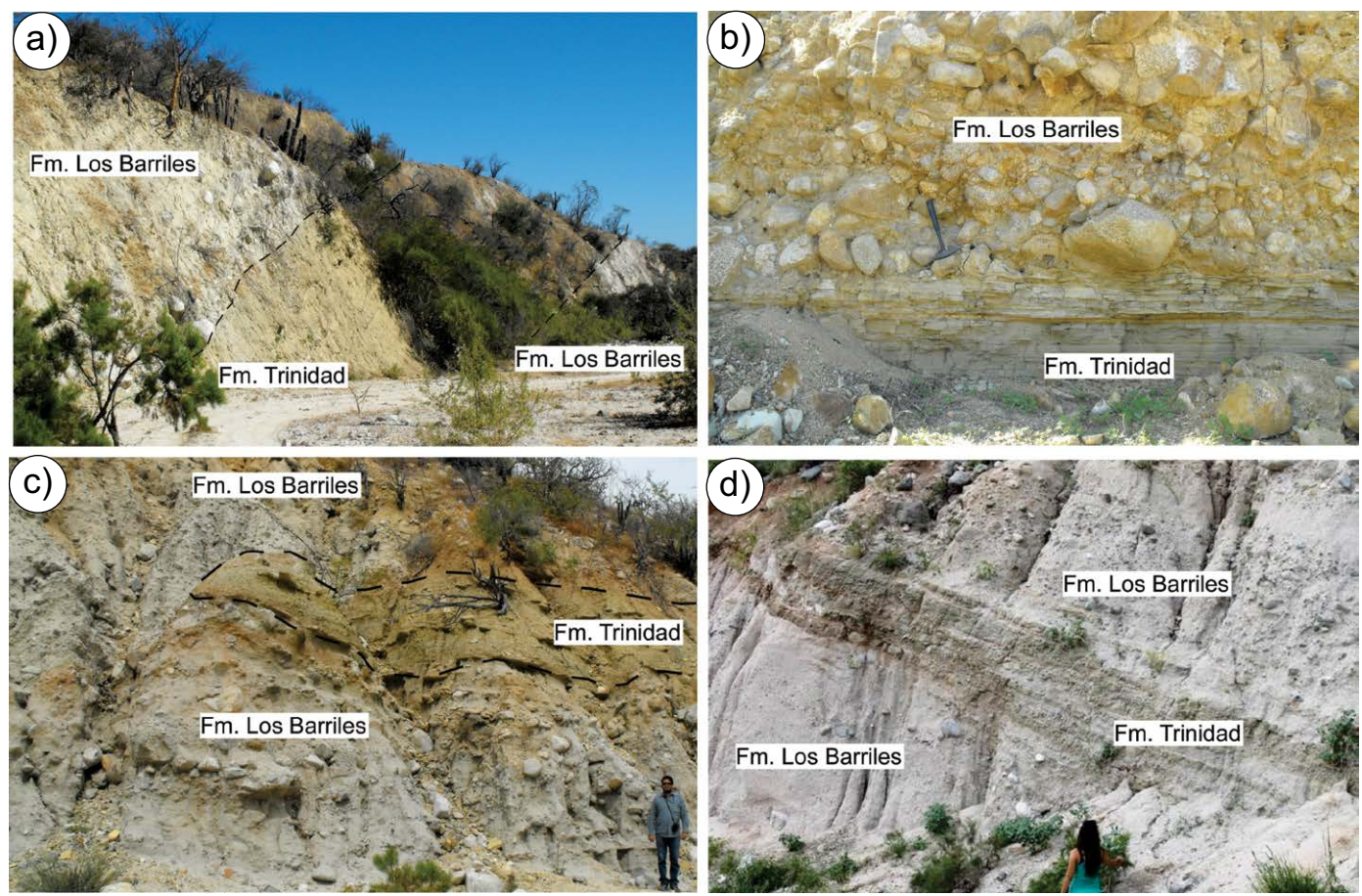

Figura 14. Interdigitación entre las formaciones Los Barriles y Trinidad: a) Localidad 70 (Figura 3). b) Localidad 102. c) Localidad 190. d) Localidad 51.

maciones Trinidad y Refugio. Esta última, a su vez, se interdigita hacia el oeste con estratos horizontales de la parte superior de la Formación Los Barriles. Dentro de la Formación Los Barriles no se observó dicha discordancia, posiblemente debido a que cerca de la falla maestra la sedimentación se dio de manera continua. Por otro lado, el contacto superior de la secuencia está dado por una discordancia erosiva angular con la secuencia estratigráfica 3.

Los estratos de la Formación Los Barriles se formaron en un ambiente de abanico aluvial, mientras que la Formación Refugio es de origen marino. Ésta última muestra poca variación textural interna, aunque tiende a exhibir materiales más gruesos en áreas cercanas a su cabecera (Tabla 3). La textura de los sedimentos, la abundancia de fósiles y de bioturbación en los estratos sugieren condiciones de aguas someras con incidencia frecuente o constante de oleaje y de corrientes.

La secuencia estratigráfica 2 al igual que la secuencia 1 fue deposi- tada en un ambiente de abanico deltaico. De acuerdo a la clasificación de Postma (1990), la Formación Los Barriles también representa a un sistema alimentador tipo A en esta secuencia estratigráfica. Sin embargo, considerando la litología de la Formación Refugio, este abanico deltaico se desarrolló en un cuerpo de agua somero y de alta energía; por lo tanto corresponde al tipo Hjulström (Postma, 1990).

\section{Secuencia estratigráfica 3}

La secuencia estratigráfica 3 está compuesta principalmente por la Formación El Chorro y en menor proporción por depósitos correspondientes a una terraza marina; ambos preservan su disposición sedimentaria original. El contacto inferior de la secuencia estratigráfica 3 consiste en una discordancia erosiva angular, la cual cubre todas las unidades más antiguas (formaciones Los Barriles, Trinidad, Refugio). La Formación El Chorro se depositó en un ambiente de abanico aluvial

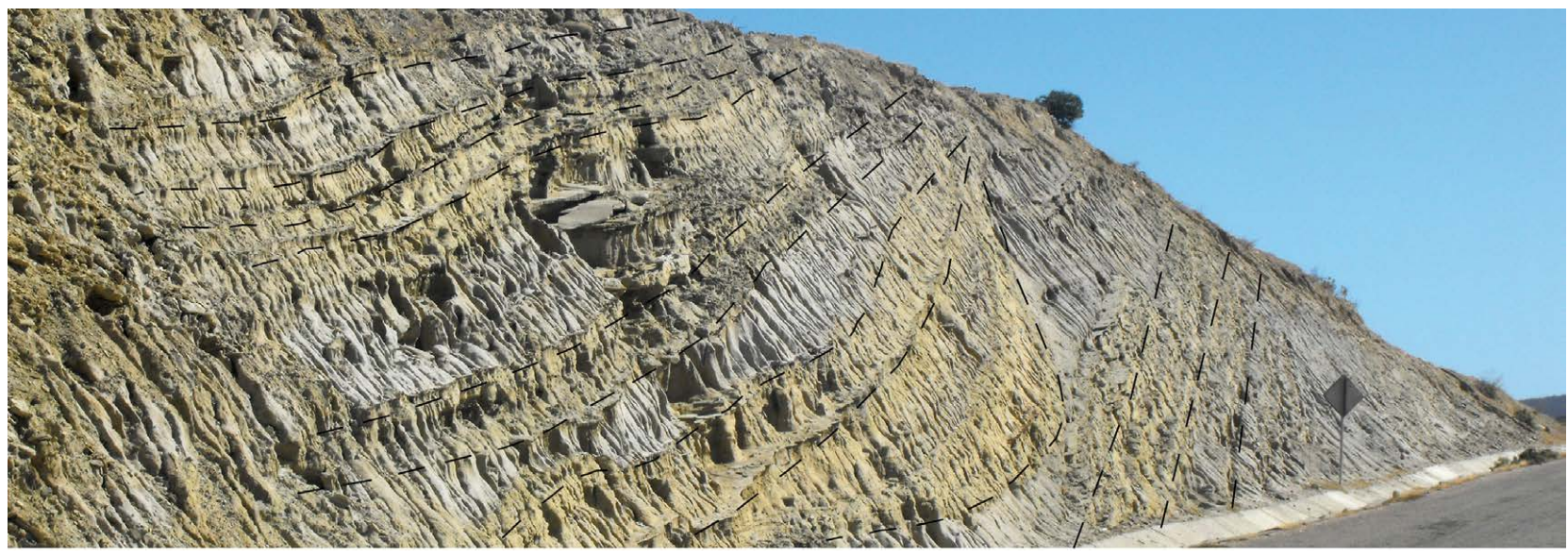

Figura 15. Paleocanal en la Formación Trinidad, facies T-LA y T-A (Figura 3: localidad 96; Tabla 2). 


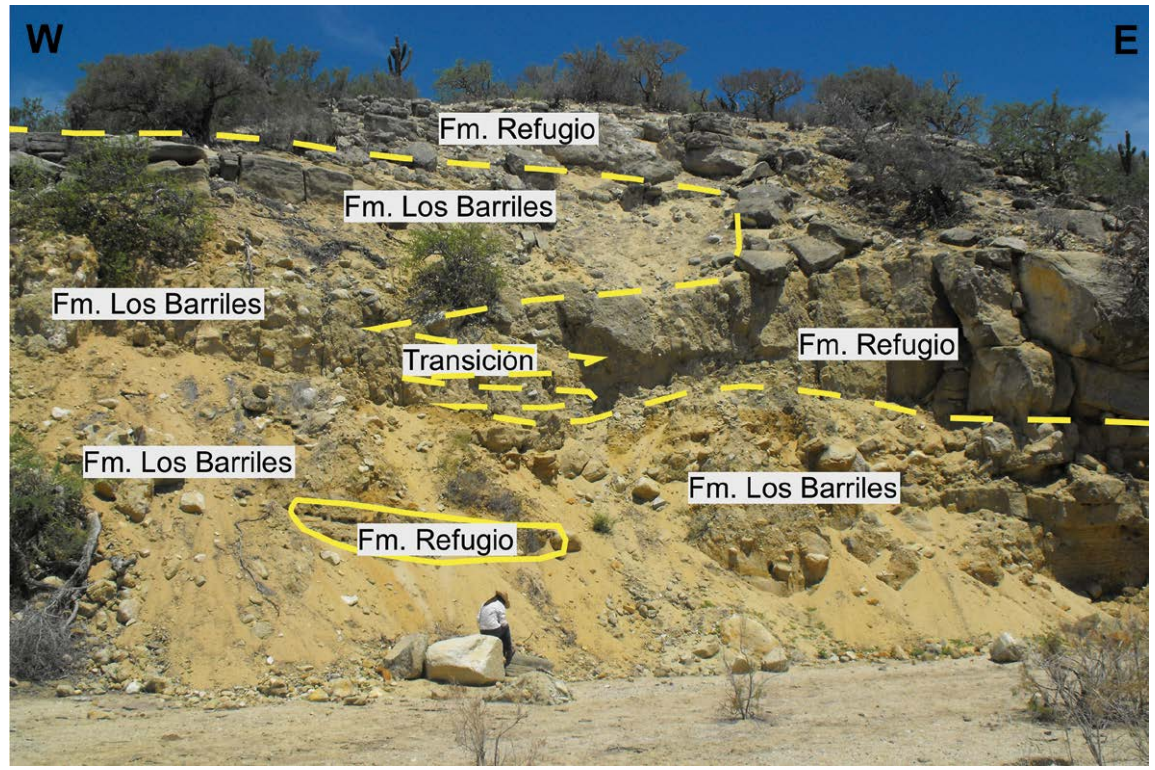

Figura 16. Interdigitación entre las formaciones Los Barriles y Refugio (Figura 3: localidad 164).

y cambia transicionalmente, de depósitos cercanos dominados por conglomerado a depósitos lejanos con mayor proporción de arenisca. Las características litológicas que presenta dicha unidad varían de un abanico dominado por flujos de escombro a un abanico fluvial trenzado, según la clasificación de Stanistreet y McCarthy (1993).

\section{EVOLUCIÓN GEOLÓGICA DE LA CUENCA}

Los datos obtenidos en el presente estudio permiten interpretar seis etapas geológicas de la evolución de la cuenca Los Barriles.

\section{Primera etapa}

La activación del sistema de fallas Los Barriles (Figura 17) empezó a finales del Tortoniano (Mioceno tardío). Este evento coincide con el inicio del fallamiento extensional en la cuenca San José del Cabo donde se generaron fallas, actualmente sepultadas hacia su parte central (Busch et al., 2011; Arreguín-Rodríguez y Schwennicke, 2013). El sistema de fallas Los Barriles está conformado por cinco segmentos (Figura 3). De éstos, los segmentos A, C, D y E presentan rumbos ligeramente variables y por lo tanto es probable que se hayan formado en un principio como fallas independientes (Gawthorpe y Leeder, 2000; Morley, 2002). El segmento B correspondería a una estructura de transferencia, con movimiento normal-oblicuo, formado sobre una rampa de relevo (Athmer y Luthi, 2011). Proponemos la contemporaneidad de esta falla con los demás segmentos del sistema marginal.

El inicio del fallamiento generó un espacio de acumulación a lo largo del sistema Los Barriles, lo cual propició erosión en el bloque de piso (sierra La Gata) y depósito en el bloque de techo (cuenca Los Barriles). En la zona próxima al escarpe morfológico, el relieve elevado propició altas tasas de erosión en el bloque de piso (Gawthorpe y Leeder, 2000; Ebinger y Scholz, 2012), formando abanicos aluviales de alto gradiente (Formación Los Barriles). Además, la rotación del bloque de techo a lo largo del sistema de fallas Los Barriles causó el levantamiento del área al este de Punta Pescadero donde, consecuentemente, también se formaron abanicos aluviales (Figura 3: localidad 108). Cabe mencionar que en esta zona el basamento, probablemente, se extendía más hacia el oriente, donde se localiza actualmente el Golfo de California. El material en estos abanicos aluviales es mayormente de origen plutónico, acarreado desde ambos márgenes de la cuenca. No obstante, la presencia de clastos metamórficos señala para este tiempo un basamento intrusivo parcialmente cubierto por rocas metamórficas (techos colgantes).

\section{Segunda etapa}

La subsidencia de la cuenca propició una incursión marina (Formación Trinidad) en ésta y, como consecuencia, la interdigitación de los abanicos aluviales con sedimentos marinos, originando abanicos deltaicos (Figura 17). Las primeras rocas marinas en la cuenca Los Barriles corresponden a una edad de NN11 (Tortoniano tardío a Messiniano) según la zonación de Martini (1971) y Backman et al. (2012). Esta asignación es similar a la edad reportada por GómezSánchez (2013) en el rancho El Torote (NN11b) en la parte central de la cuenca San José del Cabo, mientras que al occidente del rancho Los Algodones, en el sur de la cuenca San José del Cabo y cercano al rancho La Trinidad, en el área central-este, las primeras rocas marinas corresponden a NN11a (McTeague 2006; Piña-Arce, 2010). A su vez, la interdigitación entre las formaciones Los Barriles y Trinidad en el área de estudio demuestra su contemporaneidad y, por lo tanto, los estratos interdigitados de la Formación Los Barriles también tienen una edad de NN11 (Tortoniano tardío a Messiniano). Esta interpretación es reforzada por la datación de la Formación Los Barriles de Bot et al. (2016). Por lo tanto, la Formación Los Barriles es más antigua en la cuenca Los Barriles en comparación con la edad pliocénica propuesta en la cuenca San José del Cabo (Arreguín-Rodríguez y Schwennicke, 2013).

La distribución actual de facies sugiere abanicos aluviales distribuidos a lo largo de ambos márgenes de la cuenca y así como en su parte sur; como resultado, la transgresión marina creó una bahía (Figura 18). La escasa presencia de icnofósiles posiblemente puede asociarse, en parte, a condiciones variables con aguas salobres o hipersalinas durante la sedimentación. Estas supuestas restricciones oceanográficas, especialmente con oleaje limitado y mareas reducidas, explicarían también la escasez de depósitos de anteplaya en la zona de interdigitación entre las formaciones Los Barriles y Trinidad (Tabla 2). Sin embargo, la presencia de nanofósiles calcáreos en la Formación Trinidad indica condiciones marinas durante su depósito. No obstante, éstas pudieron 
no ser constantes, debido a una variación del tamaño de la conexión hacia el protogolfo. También se han mencionado condiciones restringidas en la parte basal de la Formación Trinidad, en la cuenca San José del Cabo (Smith, 1991). En general, es un fenómeno común en cuencas de rift, especialmente en su etapa temprana (Gawthorpe y Leeder, 2000).

La interacción entre subsidencia y aporte de sedimentos generó depósitos aluviales de gran espesor (Formación Los Barriles), y debido a avances y retrocesos de los abanicos deltaicos marginales, se originó una amplia zona de interdigitación con sedimentos marinos (Formación Trinidad); por lo tanto, la extensión de la zona acuática variaba a lo largo del tiempo. Paralelamente continuó el fallamiento del sistema marginal y existían fallas activas hacia el interior de la cuenca, causando el basculamiento y fallamiento sinsedimentario de las unidades (Figura $5 c-5 d$ ). Con el tiempo los depósitos de la Formación Los Barriles crecieron progresivamenete sobre los sedimentos marinos de la Formación Trinidad.

Los depósitos marinos (Formación Trinidad) en el área de estudio sugieren un ambiente marino con un gradiente suficientemente pronunciado para generar, con alta frecuencia, flujos gravitacionales por debajo del nivel base de oleaje. Este gradiente o también sismos ocasionaron inestabilidad de los sedimentos en el fondo marino (slumping; Alsop et al., 2016). De acuerdo a la clasificación de Postma (1990) y a las características litológicas de ambas unidades, el sistema corresponde a un delta tipo Gilbert de aguas profundas (ver Arquitectura de facies).

\section{Tercera etapa}

En un principio el sistema de fallas marginales Los Barriles actuó como falla normal lístrica, causando la rotación del bloque de techo con un eje de rotación paralelo al rumbo de la falla marginal. Posteriormente en la tercera etapa, el eje de rotación fue cada vez más oblicuo al rumbo de la falla, lo que generó una inclinación en las capas del relleno de la cuenca hacia el NW. Este cambio de configuración en fallas normales de cuencas de rift es un proceso común (Morley, 2002; Withjack et al., 2002) y, posiblemente, se dio por un cambio del régimen tectónico en la región del golfo (Stock y Hodges, 1989; Umhoefer, 2011).

Esta rotación causó que el sur y sureste del área de estudio quedara más elevado que el área norte donde continuó una mayor subsidencia; en consecuencia, probablemente inició erosión en la región sur. Por otro lado, en la zona norte continuó el depósito de estratos cada vez menos rotados, correspondientes a un nivel estratigráfico más alto en el bloque de techo, en comparación con las rocas en la parte sur. Además, durante el depósito del relleno de la cuenca existían múltiples fallas activas en el interior del relleno sedimentario, causando las variaciones locales en la disposición de las capas.

\section{Cuarta etapa}

Dada la continua subsidencia en el norte y noroeste de la cuenca Los Barriles, desde el oriente y nororiente nuevamente se dio una transgresión marina, creando los depósitos costeros de la Formación Refugio, los cuales sobreyacen discordantemente a estratos marinos de la Formación Trinidad (Figura 17). Estos sedimentos costeros se interdigitan lateralmente con depósitos continentales (parte superior de la Formación Los Barriles), formando un nuevo sistema de abanicos deltaicos tipo Hjulström, es decir, de aguas someras (Postma, 1990). Esta etapa probablemente ocurrió en el Plioceno temprano, considerando la edad de la secuencia 1. La litología de la Formación Refugio señala un ambiente costero de alta energía con un impacto constante del oleaje en el fondo marino. La abundancia de moluscos e icnofósiles en los depósitos indica condiciones marinas de salinidad normal y de alta energía, indicando la desaparición de los paleo-altos al oriente de la cuenca, aún existentes en la segunda etapa. También durante esta etapa, el fallamiento cesó progresivamente.
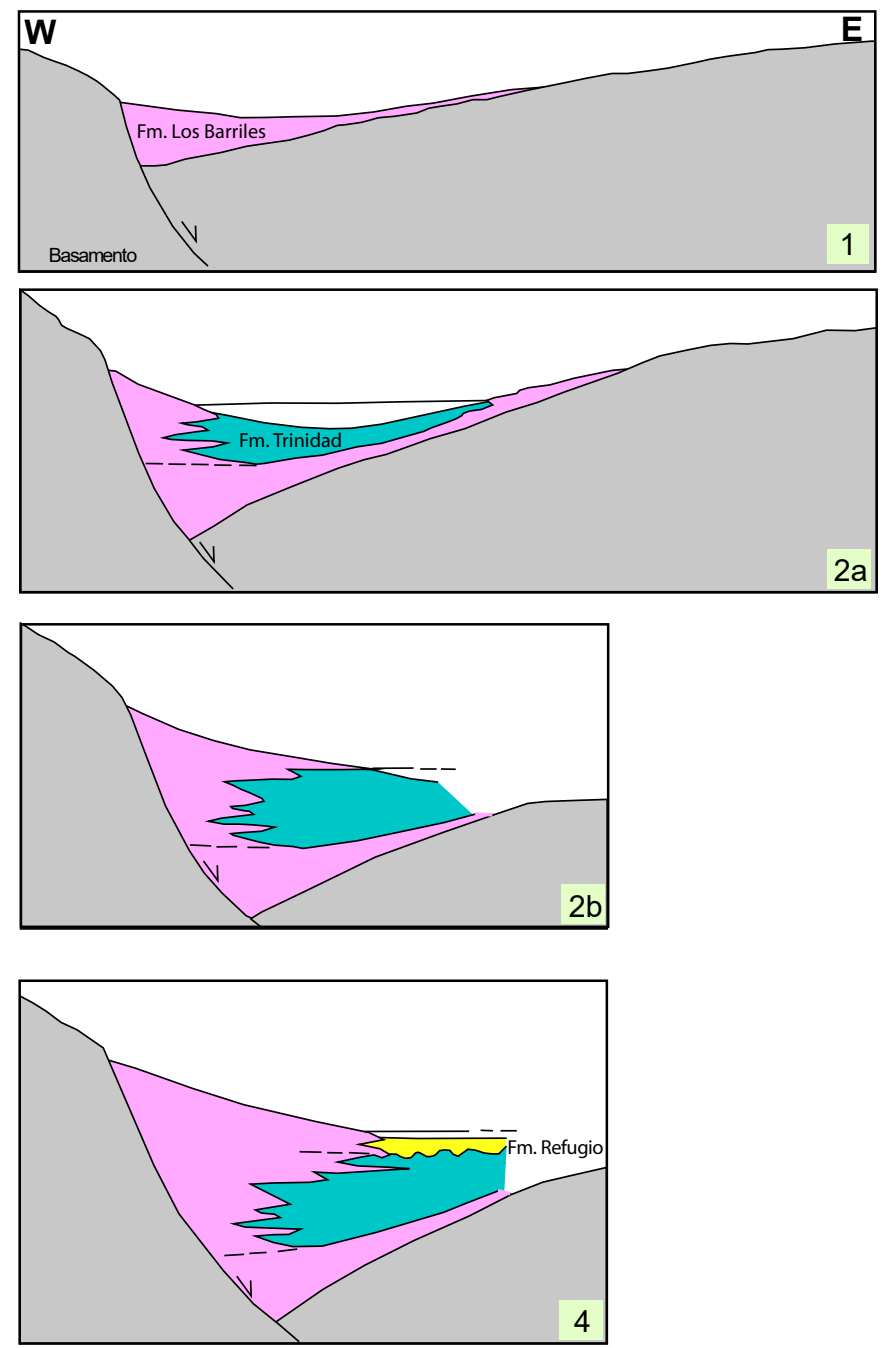

Figura 17. Evolución en la cuenca Los Barriles (ver explicación detallada en el texto). Etapa 1: inicio del fallamiento y del depósito de la Formación Los Barriles. Etapa 2a (temprana): Incursión marina, interdigitación entre las formaciones Trinidad y Los Barriles. Etapa 2b (tardía): tendencia regresiva en la cuenca y crecimiento progresivo de la Formación Los Barriles. Etapa 3 (no ilustrada): El eje de rotación del bloque de techo se vuelve más oblicuo, lo que generó una inclinación de las capas del relleno hacia el NW y erosión en el sur de la cuenca. Etapa 4: Nueva incursión marina y depósito de la Formación Refugio interdigitada con la parte superior de la Formación Los Barriles. Etapa 5 (no ilustrada): Levantamiento de la cuenca, causando erosión y posteriormente se forman depósitos aluviales de la Formación El Chorro, cubriendo discordantemente las unidades anteriores. Etapa 6 (no ilustrada): Continuación del levantamiento tectónico desde el Pleistoceno tardío y disección fluvial.

\section{Quinta etapa}

Esta etapa inició en el Plioceno con un período de erosión en toda la cuenca, que refleja la respuesta del sistema fluvial de alcanzar nuevamente su nivel base, probablemente debido a un descenso relativo en el nivel de mar. Este cambio en el nivel de mar pudo haber ocurrido por una disminución relativa y no tanto absoluta; es decir, por una inversión de la cuenca. Posteriormente, ya en la etapa post-rift (Geoffroy y Pronost, 2010; Bot et al., 2016), inició el depósito de sedimentos terrestres (Formación El Chorro) durante el Pleistoceno o incluso desde finales del Plioceno (límite Plioceno-Pleistoceno: 2.58 Ma; Gibbard et al., 2010), cubriendo discordantemente las formaciones Los Barriles, 
Trinidad y Refugio. En la región sur (el área que fue levantada en la tercera etapa), estos sedimentos rellenaron parcialmente paleovalles ya existentes y en la zona norte de la cuenca Los Barriles se originó un sistema de abanico aluvial de bajo gradiente. En esta etapa, el sistema de fallas marginales y otras fallas en el interior de la cuenca ya habían quedado casi o totalmente inactivas, con lo cual inició una erosión retrógrada (o remontante) en el bloque de piso, y en el norte de la cuenca, depósitos de la Formación El Chorro empezaron a cubrir el sistema de fallas Los Barriles. Hacia la costa actual, estos sedimentos se interdigitan difusamente con depósitos marinos costeros formados durante el último período interglacial del Pleistoceno (Ortlieb, 1991), hace aproximadamente 125,000 años (estadio isotópico 5e). Debido al clima cálido durante el clímax de este período interglacial, el nivel del mar mundial estuvo entre 5 y $6 \mathrm{~m}$ por encima del nivel actual (Muhs et al., 2003). No obstante, el descenso posterior del nivel del mar durante la última glaciación terminó la acreción vertical fluvial (Formación El Chorro) y marina; por lo tanto, la paleosuperficie de los abanicos aluviales es contemporánea al estadio isotópico $5 \mathrm{e}$.

\section{Sexta etapa}

Desde finales del Pleistoceno ocurrió un levantamiento tectónico de la península (Ortlieb, 1991) y como consecuencia, los arroyos actuales han disectado los depósitos de la Formación El Chorro, pero también de otras unidades para alcanzar su nivel base. En la región sur del área de estudio aún se preservan terrazas constituidas por depósitos de la Formación El Chorro en los valles aluviales. En la región norte se originó un arroyo sobre la traza del sistema de falla Los Barriles, así como varios canales fluviales pequeños (Figura 3).

\section{CONCLUSIONES}

La cuenca Los Barriles es un medio graben, limitado en su lado oeste por el sistema de fallas Los Barriles. Varios autores (Fletcher y Munguía, 2000; Bravo-Pérez, 2002; Busch et al., 2011) cartografiaron e interpretaron el sistema de fallas marginales de la cuenca Los Barriles como parte de la extensión norte de la falla San José del Cabo (Figura 1). Sin embargo, nuestro estudio confirma que este sistema tuvo una evolución independiente a la falla San José del Cabo, idea propuesta por Geoffroy y Pronost (2010). A partir del trabajo cartográfico se documentó la posición y la segmentación del sistema de fallas Los Barriles.

Datos bioestratigráficos en la Formación Trinidad, obtenidos en el presente estudio, y el análisis de nucleidos cosmogénicos en la Formación Los Barriles (Bot et al., 2016) revelan que el sistema de fallas Los Barriles ya estaba activa en el Mioceno tardío. Por lo tanto, su activación coincide aproximadamente o es ligeramente más

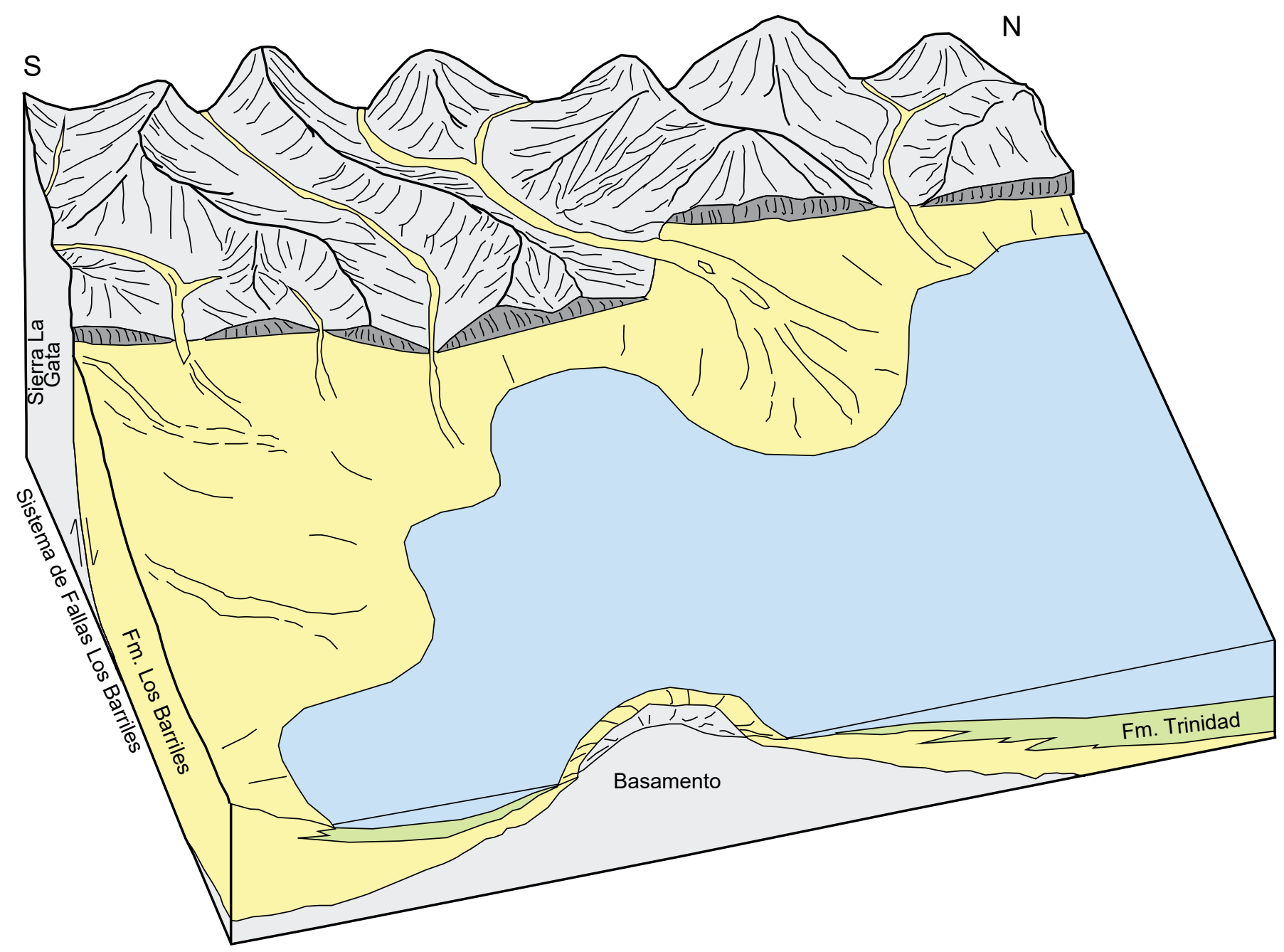

Figura 18. Modelo del ambiente de depósito en la segunda etapa de la evolución geológica en el área del estudio, correspondiendo a la secuencia 1. 
joven que el inicio del fallamiento extensional en la cuenca San José del Cabo, donde se originaron fallas actualmente sepultadas hacia su parte central (Busch et al., 2011); la activación de estas últimas marca el inicio de la exhumación acelerada hace 12-10 Ma en la sierra La Laguna (Fletcher et al., 2000).

En cambio, la falla San José del Cabo, que actualmente es la estructura marginal en la cuenca San José del Cabo (Figura 1), se originó en el Plioceno (Busch et al., 2011) y quedó activa hasta el Pleistoceno, evidenciado por la rotación de la Formación El Chorro y, además, por el aumento de su espesor hacia la falla (Arreguín-Rodríguez y Schwennicke, 2013). Por ser más joven, la falla San José del Cabo corta en la región de Buena Vista al sistema de fallas Los Barriles. Lo anterior implica que la activación del sistema Los Barriles se dio antes que la falla San José del Cabo, y no posteriormente como proponen Bot et al. (2016).

Las cuencas San José del Cabo y Los Barriles comparten las formaciones estratigráficas Los Barriles, Trinidad, Refugio y El Chorro (Figura 2). El relleno sedimentario de la cuenca fue dividido en tres secuencias estratigráficas. La primera está integrada por las formaciones Los Barriles y Trinidad, formadas durante la etapa de mayor subsidencia en la cuenca. La Formación Los Barriles se observó en contacto con el basamento en el oeste, mediante la falla marginal y, en el este, a través de una discordancia; esta formación está constituida por conglomerado y arenisca, y se formó en abanicos aluviales de alto gradiente. La Formación Trinidad se compone de lodolita y arenisca de origen marino. Ambas formaciones se interdigitan e integraron abanicos deltaicos de aguas profundas (Postma, 1990). La ausencia de capas frontales de crecimiento progresivo sugiere un desplazamiento continuo en la falla marginal. Este patrón es diferente en otras cuencas de la Provincia Extensional del Golfo, como por ejemplo la cuenca de Loreto (Mortimer et al., 2005), señalando que cada cuenca ha tenido su propia historia geológica. La edad bioestratigráfica de la secuencia 1 corresponde a NN11 (Tortoniano tardío a Messiniano; Martini, 1971 y Backman et al., 2012). Lo anterior evidencia que en la cuenca Los Barriles, la Formación Los Barriles tiene una edad más antigua que la reportada por Arreguín-Rodríguez y Schwennicke (2013) en la cuenca San José del Cabo (Figura 2)._Nuestros resultados además sugieren que en esta etapa temprana, la conexión oceanográfica con la parte central del Protogolfo de California fue restringida, posiblemente con condiciones variables de salinidad en la cuenca.

La Formación Refugio, compuesta por arenisca y conglomerado fosilífero de origen marino somero, cubre discordantemente a la Formación Trinidad, debido a la rotación oblicua del bloque de techo a lo largo de la falla marginal. Se interdigita lateralmente con la parte superior de la Formación Los Barriles, conformando la secuencia estratigráfica número 2, probablemente en el Plioceno. Ambas unidades constituyen un abanico deltaico de aguas someras (Postma, 1990). En esta etapa se originaron condiciones oceanográficas más abiertas lo que generó una mayor incidencia regular de oleaje y mayor proliferación de fauna marina.

La Formación El Chorro, con una probable edad pleistocénica, conforma la secuencia 3 y sobreyace discordantemente todas las unidades anteriores; localmente, también cubre al sistema de fallas Los Barriles. Está compuesta por arenisca y conglomerado, depositados en un ambiente de abanico aluvial y se interdigita hacia la línea de costa actual con conglomerado y arenisca fosilíferos formados durante el último período interglacial. La Formación El Chorro no presenta rotación ni fallamiento, indicando que la falla marginal ya había quedado inactiva (Bravo-Pérez, 2002).

Los alcances del presente estudio contribuyen al conocimiento sobre la estratigrafía y evolución geológica de la cuenca Los Barriles, así como también a la formación del Golfo de California.

\section{AGRADECIMIENTOS}

El Programa para el Fortalecimiento de los Cuerpos Académicos (PROMEP) apoyó nuestro proyecto (clave UABCS-CA-50, IDCA 11701). A la UABCS se agradece el apoyo brindado durante la ejecución del mismo. Agradecemos las revisiones anónimas y los comentarios de Thierry Calmus, los cuales mejoraron enormemente el presente trabajo.

\section{REFERENCIAS}

Alsop, G.I., Marco, S., Weinberger, R., Levi, T., 2016, Sedimentary and structural controls on seismogenic slumping within mass transport deposits from the Dead Sea Basin: Sedimentary Geology, 344, 71-90.

Andruleit, H., Köthe, A., Stäger, S., Bruns, A., 2000, Some comments concerning sample processing and dissolution: Journal of Nannoplankton Research, 22(3), 201

Arreguín-Rodríguez, G. de. J., Schwennicke, T., 2013, Estratigrafía de la margen occidental de la cuenca San José del Cabo, Baja California Sur: Boletín de la Sociedad Geológica Mexicana, 65(2), 481-496.

Athmer, W., Luthi, S.M., 2011, The effect of relay ramps on sediment routes and deposition: a review: Sedimentary Geology, 242(1-4), 1-17.

Atwater, T., 1970, Implications of Plate Tectonics for the Cenozoic Tectonic Evolution of Western North America: Geological Society of America Bulletin, 81, 3513-3536.

Backman, J., Raffi, I., Rio, D., Fornaciari, E., Palike, H., 2012, Biozonation and biochronology of Miocene through Pleistocene calcareous nannofossils from low and middle latitudes: Newsletters on Stratigraphy, 45(3), 221-244.

Bennett, S.E.K., Oskin, M.E., 2014, Oblique rifting ruptures continents: Example from the Gulf of California shear zone: Geology, 42(3), 215-218.

Benvenuti, M., 2003, Facies analysis and tectonic significance of lacustrine fandeltaic successions in the Pliocene-Pleistocene Mugello Basin, Central Italy: Sedimentary Geology, 157, 197-234.

Blair, T.C., 1999, Sedimentary processes and facies of the waterlaid Anvil Spring Canyon alluvial fan, Death Valley, California: Sedimentology, 46, 913-940.

Blair, T.C., 2000, Sedimentology and progressive tectonic unconformities of the sheetflood-dominated Hell's Gate alluvial fan, Death Valley, California: Sedimentary Geology, 132, 233-262.

Blair, T.C., McPherson, J.G., 1992, The Trollheim alluvial fan and facies model revised: Geological Society of American Bulletin, 104(6), 762-769.

Blair, T.C., McPherson, J.G., 1994, Alluvial fans and their natural distinction from rivers based on morphology, hydraulic processes, sedimentary processes, and facies assemblages: Journal of Sedimentary Research, A64(3), 450-489.

Blair, T.C., McPherson, J.G., 2008, Quaternary sedimentology of the Rose Creek fan delta, Walker Lake, Nevada, USA, and implications to fan-delta facies models: Sedimentology, 55, 579-615.

Bot, A., Geoffroy, L., Authemayou, C., Bellon, H., Graindorge, D., Pik, R., 2016, Miocene detachment faulting predating EPR propagation: Southern Baja California: Tectonics, 35(5), 1153-1176.

Bown, P.R., Young, J.R., 1999, Techniques, en Bown, P.R. (ed.), Calcareous Nannofossil Biostratigraphy: Dordrecht, Kluwer Academic Publishers, 16-28.

Bravo-Pérez, J.R., 2002, Segmentación de la falla San José del Cabo y su relación con la evolución tectonoestratigráfica de la cuenca San José del Cabo, Baja California Sur, México: Ensenada, Baja California, México, Centro de Investigación Científica y de Educación Superior de Ensenada, tesis de maestría, 143 pp.

Bukry, D., 1971, Discoaster evolutionary trends: Micropaleontology, 17(1), 43-52.

Bukry, D., 1973, Phytoplankton stratigraphy, Deep Sea Drilling Project Leg 20, Western Pacific Ocean, en Heezen, B.C., MacGregor, I.D., Foreman, H.P., Forristall, G., Hekel, H., Hesse, R., Hoskins, R.H., Jones, E.J.W., Kaneps, A.G., Krasheninnikov, V.A., Okada, H., Ruef, M.H. (eds.), Initial Reports Deep Sea Drilling Project, 20: Washington, United States Government Printing Office, 307-317.

Busch, M.M., Coyan, J.A., Arrowsmith, J.R., Umhoefer, P.L., Martínez-Gutiérrez, G., 2011, Normal fault basin geometries from gravity analyses in the 
La Paz-Los Cabos region, Baja California Sur, Mexico: Lithosphere, 3, 110-127.

Carreño, A.L., Smith, J.T., 2007, Stratigraphy and correlation for the ancient Gulf of California and Baja California Peninsula, Mexico: Bulletin of American Paleontology, 371, 1-146.

Carter, R.M., 1975, A discussion and classification of subaqueous mass-transport with particular application to grain-flow, slurry-flow, and fluxoturbidites: Earth Sciences Review, 11, 145-177.

Colella, A., 1988, Fault-controlled marine Gilbert type fan deltas: Geology, 16(11), 1031-1034.

Collinson, J., Mountney, N., Thompson, D., 2006, Sedimentary structures: Harpenden, Terra Publishing, 292 pp.

Contreras-Pérez, J., Ramírez-Zerpa, N., Negrete-Aranda, R., 2012, Modelos tectonoestratigráficos de las cuencas de Tiburón y Wagner en el norte del Golfo de California: Revista Mexicana de Ciencias Geológicas, 29(1), 140-157.

DeMets, C., 1995, A reappraisal of seafloor spreading lineations in the Gulf of California: Implications for the transfer of Baja California to the Pacific Plate and estimates of Pacific North America Motion: Geophysical Research Letters, 22(24), 3545-3548.

Dorsey, R.J., Umhoefer, P.J., 2000, Tectonic and eustatic controls on sequence stratigraphy of the Pliocene Loreto basin, Baja California Sur, Mexico: Geological Society of America Bulletin, 112(2), 177-199.

Dorsey, R.J., Stone, K.A., Umhoefer, P.J., 1997, Stratigraphy, sedimentology, and tectonic development of the southeastern Loreto basin, Baja California Sur, Mexico, en Johnson, M.E., Ledesma-Vázquez, J. (eds.), Pliocene Carbonates and Related Facies Flanking the Gulf of California, Baja California, Mexico: Boulder, United States of America, Geological Society of America Special Paper 318, 83-109.

Dorsey, R.J., Umhoefer, R.J., Mayer, L., 2001, Pliocene Stratigraphic evolution of the northeastern Carmen Island, Gulf of California: implications for oblique-rifting tectonics: Sedimentary Geology, 144, 97-123.

Duque-Trujillo, J., Ferrari, L., Orozco-Esquivel, T., López-Martínez, M., Lonsdale, P., Bryan, S.E., Kluesner, J., Piñero-Lajas, D., Solari, L., 2015, Timing of rifting in the southern Gulf of California and its conjugate margins: Insights from the plutonic record: Geological Society of America Bulletin, 127(5/6), 702-736.

Ebinger, C., Scholz, C.A., 2012, Continental rift basins: the East African perspective, en Busby, C., Azor-Pérez, A. (eds.), Tectonic of sedimentary basins: Recent advances: Oxford, Blackwell, 183-203.

Einsele, G., 2000, Sedimentary basins. Evolution, facies and sediment budget: Berlin, Heidelberg, Springer, 792 pp.

Ellis, C.H., 1982, Calcareous nannoplankton biostratigraphy - Deep Sea Drilling Project Leg 60, en Hussong, D.M., Uyeda, S. (eds.), Initial Reports of the Deep Sea Drilling Project, 60: Washington, United States of America, Government Printing Office, 507-536. doi: 10.2973/dsdp. proc.60.126.1982.

Falk, P.D., Dorsey, R.J., 1998, Rapid development of gravelly high-density turbidity currents in marine Gilbert type fan deltas, Loreto Basin, Baja California Sur, México: Sedimentology, 45(1), 331-349.

Fletcher, J.M., Munguía, L., 2000, Active continental rifting in southern Baja California, México; implications for plate motion partitioning and the transition to seafloor spreading in the Gulf of California: Tectonics, 19, 1107-1123.

Fletcher, J.M., Kohn, B.P., Foster, D.A., Gleadow, A.J.W., 2000, Heterogeneous Neogene cooling and exhumation of the Los Cabos block, southern Baja California: Evidence from fission-track thermochronology: Geology, 28(2), 107-110.

Fletcher, J.M., Grove, M., Kimbrough, D., Lovera, O., Gehrels, G.E., 2007, Ridgetrench interactions and the Neogene tectonic evolution of the Magdalena shelf and southern Gulf of California: Insights from detrital zircon U-Pb ages from the Magdalena fan and adjacent areas: Geological Society of America Bulletin, 119(11/12), 1313-1336.

Gans, P.B., 1997, Large-magnitude Oligo-Miocene extension in southern Sonora: Implications for the tectonic evolution of northwest Mexico: Tectonics, 16(3), 388-408.

Gartner, S., 1969, Correlation of Neogene planktonic foraminifera and calcareous nannofossil zones: Transactions of the Gulf Coast Association of Geological Societies, 19, 585-599.
Gawthorpe, R.L., Leeder, M.R., 2000, Tectono-sedimentary evolution of active extensional basins: Basin Research, 12, 195-218.

Geoffroy, L., Pronost, J., 2010, Late Pliocene to Early Quaternary extensional detachment in the La Paz-El Cabo area (Baja California Sur, Mexico): implications on the opening of the Gulf of California and mechanics of oblique rifting: Terra Nova, 22(1), 64-69.

Gibbard, P.L., Head, M.J., Walker, M.J.C., and Subcommission on Quaternary Stratigraphy, 2010, Formal ratification of the Quaternary System/Period and the Pleistocene Series/Epoch with a base at $2.58 \mathrm{Ma}$ : Journal of Quaternary Science, 25(2), 96-102.

Gómez-Sanchez, D.P., 2013, Estratigrafía de la Formación Trinidad en la localidad El Torote, Baja California Sur, México: La Paz, México, Universidad Autónoma de Baja California Sur, tesis de licenciatura, 61 pp

Haughton, P., Davis, C., McCaffrey, W., Barker, S., 2009, Hybrid sediment gravity flow deposits - Classification, origin and significance: Marine and Petroleum Geology, 26, 1900-1918.

Holt, J.W., Holt, E.W., Stock, J.M., 2000, An age constraint on Gulf of California rifting from the Santa Rosalía Basin, Baja California Sur, Mexico: Geological Society of America Bulletin, 112, 540-549.

Holz, M., Troccoli, E., Vieira, M., 2014, Sequence Stratigraphy of Continental Rift Basins I: A Conceptual Discussion of Discrepant Models, en Rocha, R., Pais, J., Kullberg, J.C., Finney, S. (eds.), STRATI 2013, First International Congress on Stratigraphy at the Cutting Edge of Stratigraphy: Heidelberg, Springer, 9-13.

MacEachern, J.A., Pemberton, S.G., Gingras, M.K., Bann, K.L., 2007, The ichnofacies paradigm: a fifty-year retrospective, en Miller, W. (ed.), Trace fossils: concepts, problems, prospects: Amsterdam, Elsevier, 52-77.

Maraver-Romero, D.A., Sevilla-Unda, V., Melendres-Rodríguez, A., AguileraHale, J.C., 2002, Carta Geológico-Minera San José del Cabo F12-2-3-5-6 Baja California Sur, escala: 1:250,000: Pachuca, Hidalgo, México, Servicio Geológico Mexicano, 1 Mapa.

Martín-Barajas, A., 2000, Volcanismo y extensión en la Provincia Extensional del Golfo de California: Boletín de la Sociedad Geológica Mexicana, LIII, 72-83.

Martín-Barajas, A., Vázquez-Hernández, S., Carreño, A.L., Helenes, J., SuárezVidal, F., Alvarez-Rosales, J., 2001, Late Neogene stratigraphy and tectonic control on facies evolution in the Laguna Salada basin, northern Baja California, Mexico: Sedimentary Geology, 144, 5-35.

Martínez-Gutiérrez, G., Sethi, P.S., 1997, Miocene-Pleistocene sediments within the San José del Cabo Basin, Baja California Sur, México, en Johnson M.E., Ledesma-Vázquez, J. (eds.), Pliocene carbonates and related facies flanking the gulf of California, Baja California, Mexico: Boulder, United States of America, Geological Society of America Special Paper, 141-166.

Martini, E., 1971, Standard Tertiary and Quaternary Calcareous Nannoplankton Zonation, en Farinacci, A. (ed.), Proceeding of the II Planktonic Conference: Roma, Italia, 739-785.

Martins-Neto, M.A., Catuneanu, O., 2010, Rift sequence stratigraphy: Marine and Petroleum Geology, 27, 247-253.

Masini, E., Robin, C., Geoffroy, L., Strzerzynski, P., 2010, The supra-detachment tectono-sedimentary record of rifted margins: the example of the Los Barriles Basin, SE Baja California Sur (resumen), en European Geological Union General Assembly 2010, Vienna, Geophysical Research Abstracts, 12, EGU2010-12049.

McCloy, C., 1984, Stratigraphy and depositional history of the San Jose del Cabo trough, Baja California Sur, Mexico, en Frizzell, V.A. Jr., (ed.), Geology of the Baja California Peninsula, Field Trip Guidebook: San Diego, Society of Economic Paleontologists and Mineralogists, Pacific Section, 39, 267-273.

McTeague, M.S., 2006, Marginal Strata of the East Central San Jose del Cabo basin, Baja California Sur, Mexico: Flagstaff, United States, Northern Arizona University, tesis de maestría, 152 pp.

Miall, A.D., 1996, The geology of fluvial deposits: sedimentary facies, basin analysis, and petroleum geology: New York, Springer, $582 \mathrm{pp}$.

Miller, M.C., Lizarralde, D., 2013, Thick evaporites and early rifting in the Guaymas Basin, Gulf of California: Geology, 41, 283-286.

Miranda-Avilés, R., Beraldi-Campesi, H., Puy-Alquiza, M.J., Carreño, A.L., 2005, Estromatolitos, tufas y travertinos de la sección El Morro: Depósitos relacionados con la primera incursión marina en la Cuenca de Santa Rosalía, Baja California Sur: Revista Mexicana de Ciencias Geológicas, 22(2), 148-158. 
Mitchum, R.M. Jr., Vail, P.R., Thompson, S., 1977, Seismic stratigraphy and global changes of sea level, part 2: the depositional sequence as a basic unit for stratigraphic analysis, en Payton, C.E. (ed.), Seismic stratigraphyApplications to hydrocarbon exploration: American Association of Petroleum Geologists Memoir, 53-62.

Morley, C.K., 2002, Evolution of large normal faults: evidence from seismic reflection data: American Association of Petroleum Geologists Bulletin, 86(6), 961-978.

Mortimer, E., Gupta, S., Cowie, P., 2005, Clinoform nucleation and growth in coarse-grained deltas, Loreto basin, Baja California Sur, Mexico: a response to episodic accelerations in fault displacement: Basin Research, $17,337-359$.

Muhs, D.R., Wehmiller, J.F., Simmons, K.R., York, L.L., 2003, Quaternary sea-level history of the United States, en Gillespie, A.R., Porter, S.C., B.F. Atwater, B.F. (eds.), The Quaternary period in the United States, 1: Amsterdam, Elsevier, 147-183.

Mulder, T., Alexander, J., 2001, The physical character of subaqueous sedimentary density flows and their deposits: Sedimentology, 48(1), 269-299.

Mulder, T., Syvitski, J.P.M., Migeon, S., Faugères, J.-C., Savoye, B., 2003, Marine hyperpycnal flows: initiation, behavior and related deposits. A review: Marine and Petroleum Geology, 20, 861-882.

Okada, H., Bukry, D., 1980, Supplementary modification and introduction of code numbers to the low-latitude coccolith biostratigraphic zonation (Bukry, 1973, 1975): Marine Micropaleontology, 5, 321-325.

Ortlieb, L., 1991, Quaternary shorelines along the northeastern Gulf of California: Geochronological data and neotectonic implications, en Jacques-Ayala, C., Pérez-Segura, E. (eds.), Studies of Sonora geology: Boulder, United States of America, Geological Society of America Special Paper 254, 95-120.

Pantoja-Alor, J., Carrillo-Bravo, J., 1966, Bosquejo geológico de la región de Santiago-San José del Cabo, Baja California: Boletín de la Asociación Mexicana de Geólogos Petroleros, 58, 1-14.

Pérez-Venzor, J.A., 2013, Estudio Geológico - Geoquímico del Borde Oriental del Bloque de los Cabos Baja California Sur, México: México, D.F., México, Universidad Nacional Autónoma de México, tesis doctoral, 297 pp.

Pérez-Venzor, J.A., Victorio-Serrano, M.A., Schwennicke, T., SantistebanMendívil, D.M., Cortés-Martínez, M.Y., 2014, La estructura tectónica falla Casas Viejas. Características e implicaciones en la evolución de la subcuenca El Cardonal, Baja California Sur (resumen) en Reunión Anual Unión Geofísica Mexicana: Puerto Vallarta, México, Geos, 34(1), 98.

Piña-Arce, M., 2010, Bioestratigrafía con Nanofósiles Calcáreos en el Área del Rancho Los Algodones, Baja California Sur, México: La Paz, B.C.S., México, Universidad Autónoma de Baja California Sur, tesis de licenciatura, 60 pp.

Plattner, C., Malservisi, R., Dixon, T.H., LaFemina, P., Sella, G.F., Fletcher, J., Suárez-Vidal, F., 2007, New constraints on relative motion between the Pacific Plate and Baja California microplate (Mexico) from GPS measurements: Geophysical Journal International, 170, 1373-1380.

Postma, G., 1984, Slumps and their deposits in fan delta front and slope: Geology, 12(1), 27-30.

Postma, G., 1990, Depositional architecture and facies of river and fan deltas: a synthesis, en Colella, A., Prior, D.B. (eds.), Coarse-Grained Deltas: Oxford, Blackwell, International Association of Sedimentologists Special Publication, 10(1), 13-27.

Postma, G., 1995, Sea-level-related architectural trends in coarse-grained delta complexes: Sedimentary Geology, 98, 3-12.

Postma, G., Nemec, W., Kleinspehn, K.L., 1988, Large floating clasts in turbidites: a mechanism for their emplacement: Sedimentary Geology, 58(1), 47-61.

Raffi, I., Backman, J., Rio, D., 1998, Evolutionary trends of tropical calcareous nannofossils in the late Neogene: Marine Micropaleontology, 35(1), 17-41.

Renaut, R.W., Gierlowski-Kordesch, E.H., 2010. Lakes, en Dalrymple, R., James, N. (eds.) Facies Models 4: Toronto, Canada, Geological Association of Canada, 541-575.

Sanders, D., 2010, Sedimentary facies and progradational style of a Pleistocene talus-slope succession, Northern Calcareous Alps, Austria: Sedimentary Geology, 228, 271-283.

Santisteban-Mendívil, D.M., 2015, Evolución estratigráfica en la subcuenca El Cardonal, al norte de Los Barriles, Baja California Sur, México: La Paz, B.C.S., México, Universidad Autónoma de Baja California Sur, Tesis de Licenciatura, $94 \mathrm{pp}$.
Schaaf, P., Böhnel, H., Pérez-Venzor, J. A., 2000, Pre-Miocene paleogeography of the Los Cabos Block, Baja California Sur: geochronological and paleomagnetic constraints: Tectonophysics, 318, 53-69.

Schwennicke, T., Umhoefer, P.J., 2008, Evolución tectonoestratigráfica a lo largo del margen oriental de la cuenca de San José del Cabo, en Primer Congreso sobre la Evolución Geológica y Ecológica del Noroeste de México: Hermosillo, Sonora, México, resumen, 107.

Schwennicke, T., Santisteban-Mendívil, D.M., Plata-Hernández, E., PérezVenzor, J.A., Cortés-Martínez, M.Y., 2015, Comparación evolutiva de abanicos deltaicos miocénicos formados en la cuenca San José del Cabo y la subcuenca El Cardonal, Baja California Sur (resumen) en Reunión Anual Unión Geofísica Mexicana: Puerto Vallarta, México, Geos, 35(1), 139.

Siesser, W.G., Bralower, T.J., Tang, C., Galbrun, B., 1992, Late MioceneQuaternary Calcareous Nannofossil biomagnetochronology on the Exmouth Plateau, Northwest Australia: Proceedings of the Ocean Drilling Program, Scientific Results, 122, 677-681.

Smith, J.T., 1991, Cenozoic marine mollusks and paleogeography of the Gulf of Califonia, en Dauphin, J.P, Simoneit, B.R.T. (eds.), The Gulf and Peninsular Province of the Californias: Tulsa, E.U., American Association of Petroleum Geologists Memoir 47, 637-666.

Stanistreet, I.G., McCarthy, T.S., 1993, The Okavango fan and the classification of subaerial fan systems: Sedimentary Geology, 85(1), 115-133.

Stock, J.M., Hodges, K.V., 1989, Pre-Pliocene extension around the Gulf of California and the transfer of Baja California to the Pacific Plate: Tectonics, 8(1), 99-115.

Sutherland, F.H., Kent, G.M., Harding, A.J., Umhoefer, P.J., Driscoll, N.W., Lizarralde, D., Fletcher, J.M., Axen, G.J., Holbrook, W.S., GonzálezFernández, A., Lonsdale, P., 2012, Middle Miocene to early Pliocene oblique extension in the southern Gulf of California: Geosphere, 8, 752-770.

Umhoefer, P.J., 2011, Why did the southern Gulf of California rupture so rapidly?-Oblique divergence across hot, weak lithosphere along a tectonically active margin: GSA Today, 21(11), 1-10.

Umhoefer, P.J., Mayer, L., Dorsey, R.J., 2002, Evolution of the margin of the Gulf of California near Loreto Baja California Peninsula, Mexico: Geological Society of America Bulletin, 114(7), 849-868.

Umhoefer, P.J., Schwennicke, T., Del Margo, M.T., Ruiz-Geraldo, G., Ingle, J.C., Mclntosh, W., 2007, Transtensional fault-termination basins: an important basin type illustrated by the Pliocene San José Island basin and related basins in the southern Gulf of California, Mexico: Basin Research, 9(2), 297-322.

Weber, J., 2012, Paleomagnetic quantification of Neogene block rotations within an active transtensional plate boundary, Baja California Sur, Mexico: Munich, Ludwig-Maximilians-Universität München, tesis doctoral, 137 pp.

Wei, W., 2003, Upper Miocene nannofossil bistratigraphy and taxonomy of Exxon core CH30-43-2 from the Gulf of Mexico: Journal of Nannoplankton Research, 25(1), 17-23.

Wilson, I.F., Rocha, V.S., 1955, Geology and Mineral Deposits of the Boleo Cooper district Baja California, Mexico: Washinton D.C., United States of America, Geological Survey Professional Paper, 273, 134 pp.

Withjack, M.O., Schlische, R.W., Olsen, P.E., 2002, Rift-Basin structure and its influence on sedimentary systems, en Renaut, R.W., Ashley, G.M. (eds.), Sedimentation in Continental Rifts: Tulsa, E.U., Society for Sedimentary Geology Special Publication, 73, 57-81.

Young, J.R., 1999, Neogene, en Bown, P.R. (ed.), Calcareous Nannofossil Biostratigraphy: Dordrecht, Kluwer Academic Publishers, 225-241.

Zanchi, A., 1994, The opening of the Gulf of California near Loreto: from basin and range extension to transtensional tectonics: Journal of Structural Geology, 16, 1619-1639.

Manuscrito recibido: marzo 3, 2017

Manuscrito corregido recibido: agosto 18, 2017

Manuscrito aceptado: agosto 23, 2017 